\title{
Dendrite-free alkali-metal electrodeposition from contact-ion-pair state induced by mixing alkaline earth cation
}

\author{
Hongyi $\mathrm{Li}^{1,2 *}$, Masaki Murayama ${ }^{1}$ and Tetsu Ichitsubo ${ }^{1,2 *}$ \\ ${ }^{1}$ Structure-Controlled Functional Materials Laboratory, Institute for Materials Research, Tohoku University. \\ ${ }^{2}$ Collaborative Research Center on Energy Materials, Institute for Materials Research, Tohoku University.
}

\begin{abstract}
Alkali metals, such as lithium and sodium, have been expected to be used for rechargeable metal-anode batteries owing to their low electrode potentials and large capacities. However, the well-known fatal problem, "dendritic growth" causing a dangerous short circuit, is faced while charging the batteries. Here, through a comprehensive study with electrochemical experiments, Raman and soft X-ray emission spectroscopies, density-functional-theory calculation, and molecular dynamic simulations, we provide an advanced guideline for electrolyte design in which a mixture of alkaline earth $(\mathrm{Mg}, \mathrm{Ca}, \mathrm{Ba})$ salts is used to inhibit dendrite growth of alkali metals $\left(\mathrm{Li}, \mathrm{Na}\right.$ ) during electrodeposition. Especially, focusing on $\mathrm{CaTFSA}_{2}$ as a salient exemplary alkaline-earth-cation additive, we demonstrate that dendrite-free morphology upon alkali-metal electrodeposition can successfully be attained by modifying their solvation structures in the dual-cation electrolyte systems. Adding divalent $\mathrm{Ca}^{2+}$ promotes alkali cation $\left(\mathrm{Li}^{+}\right.$or $\mathrm{Na}^{+}$) to form the contact ion pairs (CIPs) with the counter anions, which replaces the solvent-separated ion pairs (SSIPs) commonly existing in single-cation electrolytes. Such CIPs related to alkali cations would separate $\mathrm{Ca}^{2+}$ ions distantly to shield the strong coulomb interaction among the divalent cations. The stronger binding of the CIPs would retard the desolvation kinetics of alkali cations and, consequently, realizes a severely constrained alkali-metal electrodeposition in a reaction-limited process that is required for the dendrite-free morphology. This work provides prospects to construct dual-cation electrolytes for dendrite-free alkali-metal-anode batteries utilizing the concerted interactions between monovalent and multivalent cations.
\end{abstract}

\section{- INTRODUCTION}

Safe and low-cost rechargeable batteries are indispensable towards settling the environmental and energy concerns.1,2 Alkali metal elements, such as $\mathrm{Li}, \mathrm{Na}, \mathrm{K}$, have been considered as promising carrier ions to construct metal-anode rechargeable batteries, ${ }^{3,4}$ because their low redox potentials and high capacities are beneficial for increasing the battery energy density. For the cathodes, various intercalation/convention-type active materials with high energy densities and cyclabilities have been reported, owing to the advanced structural analysis and the theoretical computation methods in recent years. ${ }^{5-7}$ However, for the anodes, the ideal alkali metal anodes can hardly be employed practically. This is because the well-known "dendritic growth" phenomena leads to low reversibility of the deposition/dissolution reactions and severe safety risks ${ }^{8-10}$; during charging the batteries, electrodeposits are usually formed to be long and sharp dendrites, which easily peel off from the electrode surface and penetrate the separator, resulting in remarkable degradation in coulomb efficiency and internal short circuit of the batteries. ${ }^{11}$ Currently, carbonaceous and alloy anode materials are used to collect the cations during the electrode reactions. ${ }^{12-14}$ These intercalation-type or alloy-type anode materials take advantage of their intrinsic excellent electron and ionic conductivity and high chemical stability. However, compared to the alkali metal anodes, the non-active host additives inevitably increase the battery weight and, therefore, decrease the electrode energy density. ${ }^{14-16}$ Thus, if it is possible to control the electrodeposition morphology, it will be a game-changing achievement toward innovative battery technologies utilizing alkali metal anodes. ${ }^{3}$

Generally, dendritic morphology tends to be formed when crystallization or solidification occurs in a diffusionlimited condition, where the mass transfer governed by the driving force (e.g., temperature difference, electric field, etc.) cannot compensate for depletion at/around the growth interface. Particularly, for the alkali metal anodes, electrodeposition can be typically divided into an initial reaction-limited process (desolvation and reduction of $\mathrm{Li}^{+}$or $\mathrm{Na}^{+}$on the surface) and subsequent diffusion-limited process $\left(\mathrm{Li}^{+}\right.$or $\mathrm{Na}^{+}$transport from the bulk electrolyte to the surface) ${ }^{17-19}$ Borderline that divides the two modes is the timing (usually called as the Sand's time ${ }^{17,20}$ ) when the surface $\mathrm{Li}^{+}$concentration reaches zero. At the reaction-limited stage, the crystal morphology is usually mossy or whiskerlike, which highly depends on the stability, and the electron and ionic conductivity of solid-electrolyte interphase $(\mathrm{SEI})^{21}$. Whereas, at the diffusion-limited stage, needle-like 
crystals forming the dangerous dendritic morphology are usually grown synergistically accompanying the electric and/or diffusion fields localized towards the tip of the deposits. $^{22,23}$

Since the ionic transport and chemical reactivity upon electrodeposition highly depend on the properties of the electrolytes, a large number of efforts have been made to explore suitable salts and solvents for non-dendritic alkali metal anodes. ${ }^{24-28}$ For example, salt-concentrated (>3-5 M) electrolytes ${ }^{28,29}$ are known to be effective for avoiding the dendritic growth and enhancing the cyclability of Li metal anodes. Besides, as intriguing alternative strategies, combining different cation elements, e.g. (alkali-alkali) $\mathrm{Li}-\mathrm{Cs}^{30}$, Li-Na ${ }^{33}$, (alkali-alkaline earth) Li-Mg ${ }^{31,32}$, have been claimed to have remarkable effects on suppressing the dendritic growth. Compared to the former salt-concentrated electrolytes, the dual-cation electrolytes are usually used at low concentrations, which would be beneficial in wide operating conditions and reducing the production cost. Until now, the effects of the dual-cation electrolytes have usually been explained as electrostatic absorption of the additive cations on the electrode surface ${ }^{30,33}$. However, the alkali metals other than Li have similar redox potentials and the monovalent alkali cations are easily electrodeposited in terms of desolvation as well as monovalent Li; therefore, it would be generally difficult to control and distinguish the electrodeposition according as the species of alkali metals. On the other hand, since $\mathrm{Li}$ and $\mathrm{Mg}$ can form the solid solutions in wide composition ranges, $\mathrm{Mg}$ that has a higher redox potential can be involved in the Li-Mg alloy formed upon electrodeposition; nevertheless, there is an empirical fact that divalent cation is difficult to be electrodeposited rather than monovalent alkali cations, which is an advantageous point for single-cation electrodeposition under an altered solvation-structure environment. Thus, fundamental mechanisms of the electrodeposition in the dual-cation (alkali and alkaline earth) electrolytes must be unveiled towards further development and applications.

In this work, to establish the design guidelines of the dualcation technologies employing the electrolytes consisting of alkali metal ( $\mathrm{Li}, \mathrm{Na}$ ) and alkaline earth metal $(\mathrm{Mg}, \mathrm{Ca}, \mathrm{Ba})$, we investigated how the interactions between different cations and anions affects the electrodeposition behavior of alkali metals. Especially focusing on divalent $\mathrm{Ca}^{2+}$ cation as an exemplary alkaline-earth-cation additive, we demonstrate that dendritic Li or Na metal electrodeposits observed in the Li or Na single-cation electrolytes dramatically change to be flat and smooth morphology in Li-Ca or Na-Ca dual-cation electrolytes. This is owing to the fact that the electrodeposition kinetics is moderated in the dual-cation electrolytes. Raman spectroscopy and molecular dynamics (MD) simulations demonstrate that $\mathrm{Ca}^{2+}$ cations play a crucial role in modifying the solvation structure; $\mathrm{Li}^{+}$or $\mathrm{Na}^{+}$cations, intervening between the $\mathrm{Ca}^{2+}$ cations, tend to form stronger contact ion pairs (CIPs) with the anions, substituted for primary solvent-separated ion pairs (SSIPs). The modified solvation structure increases the desolvation energy of $\mathrm{Li}^{+}$or $\mathrm{Na}^{+}$cations and, consequently, keep the electrodeposition in a reaction-limited process. Utilizing the interactions among the different cation species would contribute to constructing safe and low-cost metal-anode rechargeable batteries.

\section{- RESULTS AND DISCUSSION}

Electrodeposition in dual-cation electrolytes. The electrolytes were prepared by using alkali-metal-TFSA (LiTFSA, NaTFSA, CaTFSA ${ }_{2}$ ) salts as the solutes (TFSA: bis(trifluoromethanesulfon)imide, $\left.\left[\mathrm{N}\left(\mathrm{SO}_{2} \mathrm{CF}_{3}\right)_{2}\right]^{-}\right)$and a chain-like ether G3 as the solvent (G3: triethylene glycol dimethyl ether, $\mathrm{C}_{8} \mathrm{H}_{18} \mathrm{O}_{4}$ ). The $\mathrm{O}$ atoms in the chain molecules chelate the cations upon the salt dissolution. ${ }^{34}$ Compared to the complicated solvation in conventional carbonate solvents, the TFSA $/ \mathrm{G} 3$ electrolytes facile the investigation on the interaction between different cations. For convenience, hereafter we abbreviate the electrolytes as follows; for example, "the Li electrolyte" denotes an electrolyte containing 0.5 mol LiTFSA per $1 \mathrm{~L}$ of G3, and "the Li-Ca electrolyte" stands for an electrolyte containing 0.5 mol LiTFSA and 0.5 mol CaTFSA 2 (totally containing $1 \mathrm{~mol}$ of TFSA salt) per $1 \mathrm{~L}$ of G3, and so on.

To investigate the effects of adding Ca salt, we first conducted constant potential (chronoamperometry) electrodeposition experiments in the $\mathrm{Li}, \mathrm{Na}, \mathrm{Ca}$ single-cation and the Li-Ca, Na-Ca dual-cation electrolytes. Figure 1a illustrates a three-electrodes beaker cell used in the electrodeposition experiments. $\mathrm{Cu}$ foil was used as the working electrode (WE) to collect the electrodeposits. For the reference electrode (RE) and the counter electrode (CE), Li and $\mathrm{Na}$ metal was used in the $\mathrm{Li}, \mathrm{Li}-\mathrm{Ca}$ and $\mathrm{Na}$, Na-Ca electrolyte, respectively. In the Ca electrolyte, Ca metal was employed as $\mathrm{CE}$, and a Li reference electrode (Li RE) was used, as illustrated in the right in Figure 1a. In the Li RE, a Li foil was immersed in $0.5 \mathrm{~mol} \mathrm{~L}^{-1}$ LiTFSA/G3 which was separated to the bulk electrolyte by a ceramic filter.

Figures $\mathbf{1 b}$ and $\mathbf{1 c}$ show the chronoamperometry profiles during electrodeposition in the $\mathrm{Li}, \mathrm{Li}-\mathrm{Ca}$ and the $\mathrm{Na}, \mathrm{Na}-\mathrm{Ca}$ electrolytes, respectively; the inset in Figure $1 \mathrm{~b}$ shows the profile for the Ca electrolyte. The electrodeposition potentials in the chronoamperometry measurements were set for $-0.5 \mathrm{~V}$ vs. $\mathrm{Li}$ in the $\mathrm{Li}, \mathrm{Ca}, \mathrm{Li}-\mathrm{Ca}$ electrolytes and $-0.5 \mathrm{~V}$ vs. $\mathrm{Na}$ in the $\mathrm{Na}$, Na-Ca electrolytes. The electrodeposition was stopped when the areal capacity reached $5 \mathrm{mAh} \mathrm{cm}^{-2}$ except for the Ca electrolyte, where the current density for Ca was almost zero and no obvious deposit was observed (Figure 1d). The previous studies ${ }^{35,36}$ indicate that $\mathrm{Ca}$ deposition hardly occurs in the CaTFSA 2 electrolyte, because the solidelectrolyte interphase (SEI) layer formed on the electrode impedes the $\mathrm{Ca}^{2+}$ transport ${ }^{36}$. The exchange reaction of $2 \mathrm{Li}$ $+\mathrm{Ca}^{2+}=2 \mathrm{Li}^{+}+\mathrm{Ca}$ is also significantly suppressed, which enables us to use Li metal as the RE and CE in the Li-Ca electrolyte (see Figure S1). The current-density profiles obtained for both the $\mathrm{Li}$ and $\mathrm{Na}$ electrolytes (green curve in Figure $1 \mathrm{~b}$ and blue one in Figure 1c) are found to be obviously unstable and large compared to those in the Li-Ca and $\mathrm{Na}-\mathrm{Ca}$ electrolytes (orange curve in Figure $1 \mathrm{~b}$ and pink one in Figure 1c). The unstable currents in the Li and Na electrolytes reflect the crystal growth in the dendritic form. As shown in the left of Figures 1e and 1f, most of the deposits (Li or Na metal) were floating in the single-cation ( $\mathrm{Li}$ or $\mathrm{Na}$ ) 


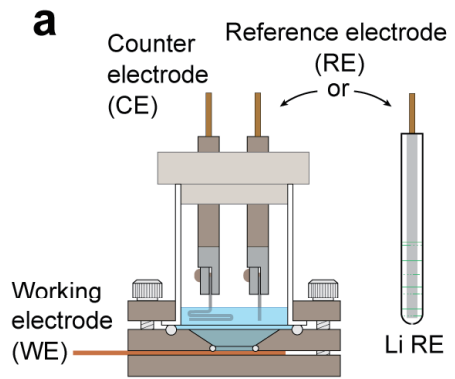

Standard electrode potential / V vs. SHE

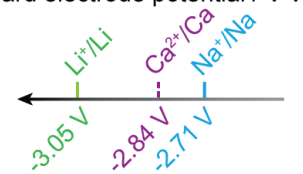

d

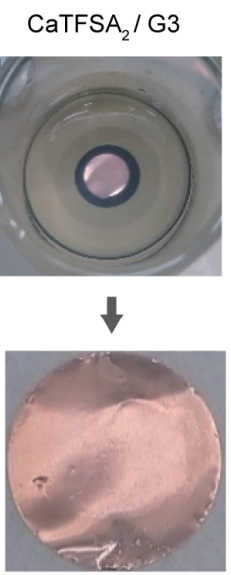

No electrodeposits

e b
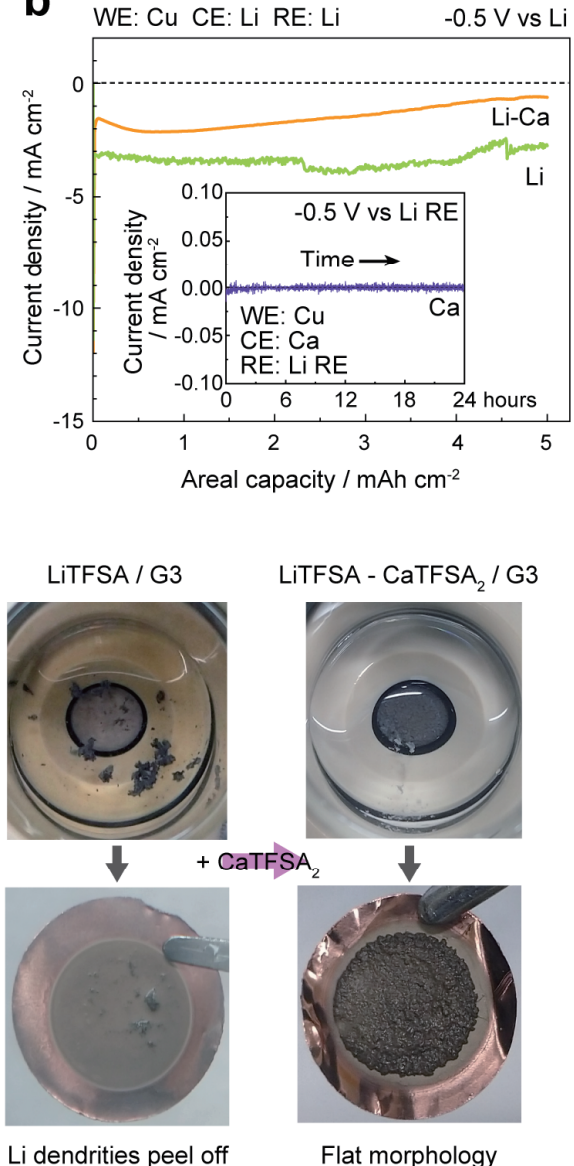

C

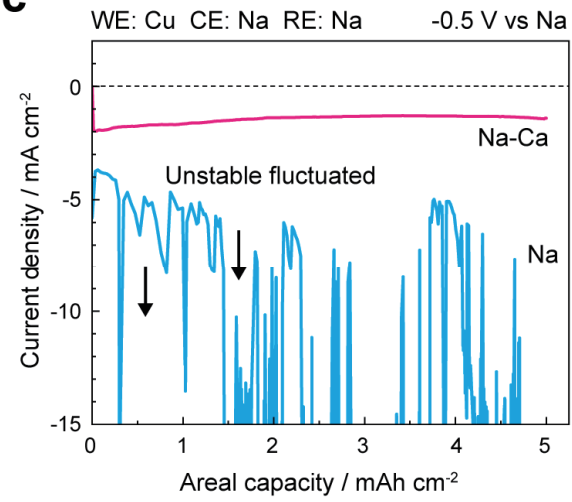

f

NaTFSA / G3 NaTFSA - CaTFSA I $_{2} 3$
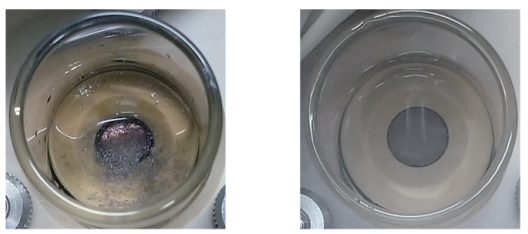

$\downarrow+$ CarF\$A 2

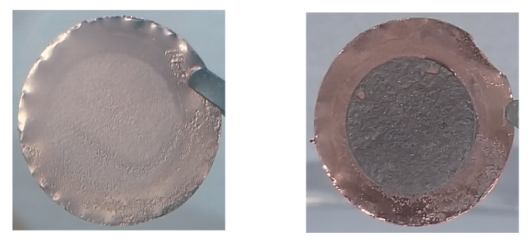

Na dendrities peel off

Flat morphology

Figure 1. Electrodeposition behavior in Li-Ca and Na-Ca dual-cation electrolytes. (a) Construction of the three-electrode beaker cell used in the electrodeposition experiments. $\mathrm{Cu}$ foil was employed as a working electrode (WE) to collect the deposits. Lower shows the standard electrode potentials (V vs. standard hydrogen electrode, SHE) of $\mathrm{Li}^{+} / \mathrm{Li} \mathrm{Ca}^{2+} / \mathrm{Ca} \mathrm{Na}^{+} / \mathrm{Na}$ for reference. Current-density profiles of constant potential electrodeposition obtained for (b) LiTFSA/G3 and LiTFSA-CaTFSA2/G3 at -0.5 V vs Li, and (c) NaTFSA/G3 and NaTFSA-CaTFSA2/G3 at - $0.5 \mathrm{~V}$ vs Na. In the dual-cation cases, the addition of CaTFSA2 significantly stabilizes the current density during electrodeposition of alkali metals. Inset in (b) shows the current profile for $\mathrm{Cu}-\mathrm{WE}$ in $\mathrm{CaTFSA} / \mathrm{G} 3$ at $-0.5 \mathrm{~V}$ vs Li; almost zero current indicates that Ca cannot be practically electrodeposited. Photos of WEs after electrodeposition in (d) CaTFSA $_{2}$ /G3, (e) LiTFSA/G3 and LiTFSA-CaTFSA 2 /G3, and (f) NaTFSA/G3 and NaTFSA-CaTFSA $/$ G3. The floating deposits observed in LiTFSA/G3 and NaTFSA/G3 were significantly suppressed in the cases where CaTFSA 2 salt was added. Each salt concentration in all the electrolytes was $0.5 \mathrm{~mol} \mathrm{~L}^{-1}$.

electrolyte, being detached from the $\mathrm{Cu}$ foil. The weak bonding of the Li and Na dendrites with the $\mathrm{Cu}$ foils would be easily broken by collisions between the crystals. Since the density of $\mathrm{Li}\left(0.535 \mathrm{~g} \mathrm{~cm}^{-3}\right)$ and $\mathrm{Na}\left(0.968 \mathrm{~g} \mathrm{~cm}^{-3}\right)$ are lower than that of the $\mathrm{G} 3$ solvent $\left(0.986 \mathrm{~g} \mathrm{~cm}^{-3}\right)$, deposits peeled off from the $\mathrm{Cu}$ foil floats into the electrolytes, leading to dramatic changes in the effective surface area and causing such an unstable fluctuation of the current. Besides, floats in the $\mathrm{Na}$ electrolyte are found to be finer than those in the Li. electrolyte, suggesting higher reactivity and fragility of Na dendrites $^{37}$

Contrary to the above cases of dendrite formation, interestingly, such floats were dramatically suppressed in the Li$\mathrm{Ca}$ and Na-Ca electrolytes (right in Figure 1e and 1f), resulting in the smooth dendrite-free morphology. Such uniform morphology would strongly reflect the "stable" current density, which is desired for the safe use of metal anodes. Similar results were also obtained in the constant-current (chronopotentiometry) condition of electrodeposition at 2 $\mathrm{mA} \mathrm{cm}-2$; see Figure S2. This demonstrates that constructing dual-cation systems is a quite effective approach to suppress the fatal dendritic growth of alkali metal anodes.

The electrodeposits obtained in the chronoamperometry tests were further observed using a field-emission scanning electron microscope (FE-SEM). Compared to the dendrites in the $\mathrm{Li}$ and $\mathrm{Na}$ electrolytes (Figures $\mathbf{2 a}$ and $\mathbf{2 b}$ ), electrodeposits in the Li-Ca and Na-Ca electrolytes (Figures 2c and 2d) are found flat and rather smooth from the front view and densely bulky from the cross-section view. The respective ratios of $\mathrm{Li}$ or $\mathrm{Na}$ to $\mathrm{Ca}$ in the deposits were measured by inductivity coupled plasma (ICP) analysis; both the molar ratio of $\mathrm{Li}: \mathrm{Ca}$ and $\mathrm{Na}$ : Ca were about 9:1, as shown in 


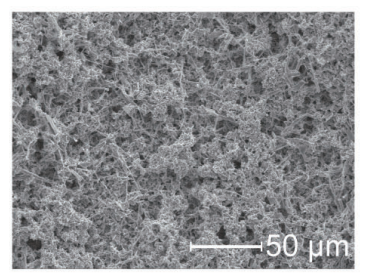

b NaTFSA / G3

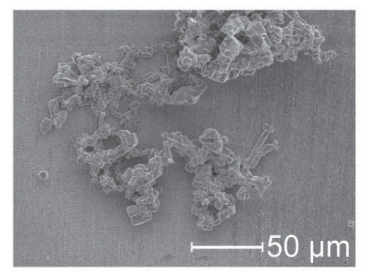

c LiTFSA-CaTFSA ${ }_{2}$ / G3

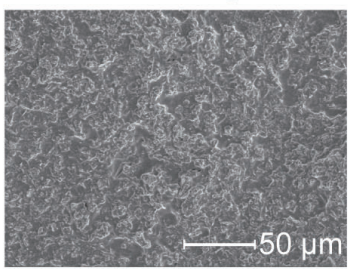

d NaTFSA-CaTFSA $/$ / G3

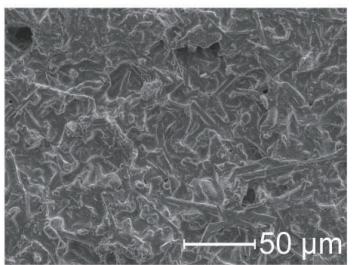

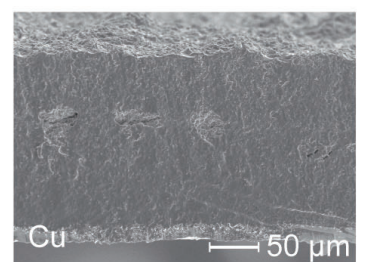

Cross

section

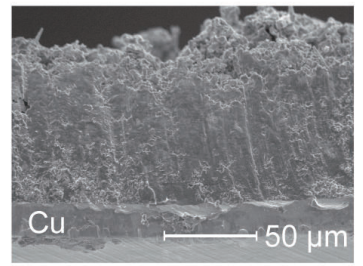

g $\mathrm{Li}-\mathrm{Ca}$

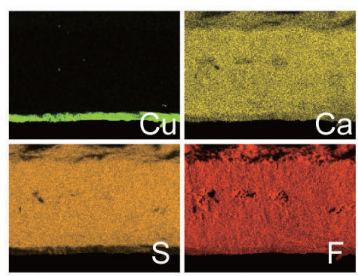

h $\mathrm{Na}-\mathrm{Ca}$

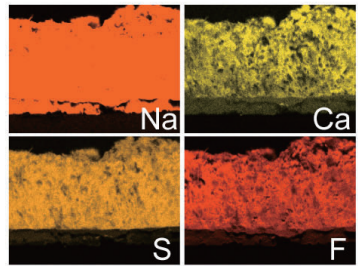

e

\begin{tabular}{ccc}
\multicolumn{3}{l}{ Composition / at.\% } \\
\hline & $\mathrm{Li}$ & $\mathrm{Ca}$ \\
\hline $\mathrm{ICP}$ & 89.4 & 10.6 \\
\hline & & \\
\hline & $\mathrm{Na}$ & $\mathrm{Ca}$ \\
\hline $\mathrm{ICP}$ & 89.1 & 10.9 \\
XRF & 85.0 & 15.0 \\
\hline
\end{tabular}

f

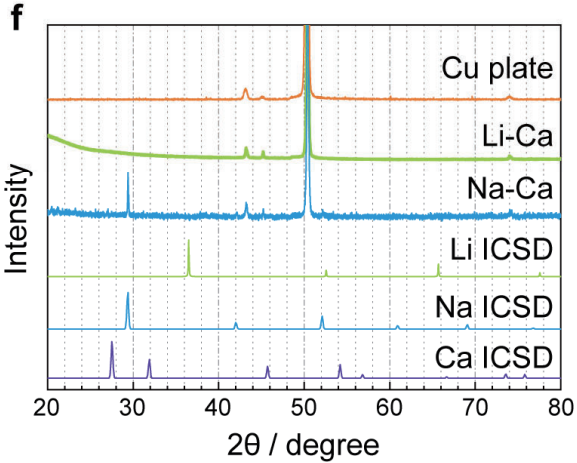

i

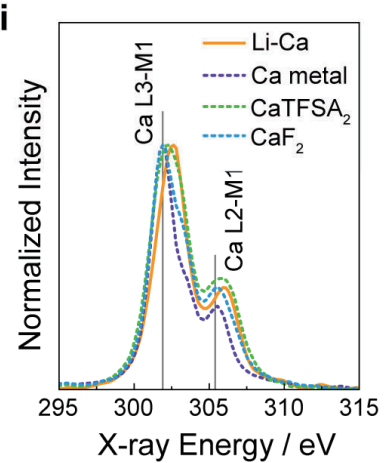

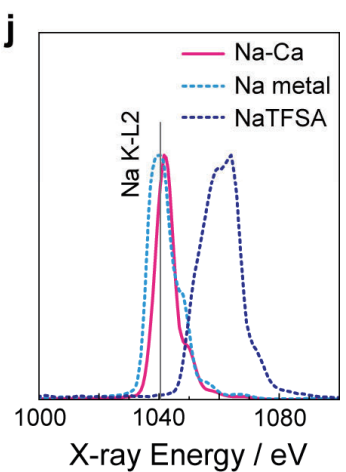

Figure 2. Morphology, structure, chemical composition, and valence state of electrodeposits obtained in various electrolytes. The scanning electron spectroscopy (SEM) images of deposits in (a) LiTFSA/G3, (b) NaTFSA/G3, (c) LiTFSA-CaTFSA2/G3, and (d) NaTFSA-CaTFSA $_{2} /$ G3. Electrodeposition morphology was significantly uniformed in the dual-cation electrolytes. (e) Chemical composition of the deposits in dual-cation electrolytes, measured by inductivity coupled plasma (ICP) spectroscopy and X-ray fluorescence (XRF) analysis, where Li or Na was the major component in the deposits. (f) X-ray diffraction (XRD) patterns of the electrodeposits in LiTFSA-CaTFSA 2 /G3 and NaTFSA-CaTFSA $/$ G3. Energy dispersive X-ray (EDX) spectroscopy mapping of the cross section view of the electrodeposits in (g) LiTFSA-CaTFSA $2 / G 3$ and (h) NaTFSA-CaTFSA2/G3. The EDX mapping areas are the same as those shown in (b) and (d). Soft X-ray emission spectra (SXES) of Ca L3-M1 (2p $p_{3 / 2}$ to $\left.3 s\right)$ and L2-M1 (2p $p_{1 / 2}$ to $\left.3 s\right)$ peaks of the deposits in (i) the Li-

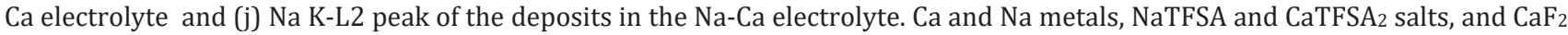
were measured as refences. It is suggested that Ca in the electrodeposits is in the oxidized state and Na is in the reduced metal state. Each salt concentration in all the electrolytes was $0.5 \mathrm{~mol} \mathrm{~L}^{-1}$.

the tables in Figure 2e. The Na : Ca ratio was also confirmed using X-ray fluorescence (XRF) measurement, being close to that measured by ICP. These results indicate that certain amount of $\mathrm{Ca}$ is also involved into the deposits. However, the X-ray diffraction (XRD) patterns in Figure $2 \mathbf{f}$ shows that no obvious XRD peaks coming from Ca-metal crystals or alloy phases are observed in all the cases. Thus, it is suggested that this small amount of Ca would be involved in the deposits, being in the salt state (described later for details). The XRD peaks originating from bcc Na metal are clearly seen in the case of the Na-Ca electrolyte, but this is not the case for the Li-Ca electrolyte since the Li can hardly be detected by laboratory X-ray apparatuses, but the flat and smooth electrodeposit surely consists of mainly Li in terms of the chemical composition analyses.
Furthermore, energy dispersive X-ray (EDX) spectroscopy was conducted to map the Ca distribution in the deposits. Figures $\mathbf{2 g}$ and $\mathbf{2 h}$ show the element mappings of the cross sections of the deposits in $\mathrm{Li}-\mathrm{Ca}$ and $\mathrm{Na}$-Ca electrolytes, respectively. The Ca concentration is almost uniform in the cross sections, as well as the distributions related to the elements $\mathrm{F}$ and $\mathrm{S}$. The molar ratio of $\mathrm{Ca}: \mathrm{S}: \mathrm{F}$ is about 1 : $2.35: 7.37$ in Li-Ca case and $1: 2.83: 8.93$ in the Na-Ca case based on the EDX spectra. Since the stoichiometric ratio of $\mathrm{Ca}: \mathrm{S}: \mathrm{F}$ in the CaTFSA 2 salt, $\mathrm{Ca}\left(\mathrm{C}_{2} \mathrm{~F}_{6} \mathrm{NO}_{4} \mathrm{~S}_{2}\right)_{2}$, is $1: 4: 12$, the Ca component in the deposits would be attributed to the remaining chemical species related to the electrolyte confined into the electrodeposits. Another possibility is that the reduced $\mathrm{Ca}$ atoms are mixed in the $\mathrm{Li}$ or Na matrix, and the detected $\mathrm{S}$ and $\mathrm{F}$ elements are derived from the electrolyte decomposition. In order to identify the chemical state of $\mathrm{Ca}$, we carried out soft X-ray emission spectroscopy (SXES). 
Figure $2 \mathbf{i}$ shows the SXES results of the L3-M1 and L2-M1 emissions of the Ca in the electrodeposits in the Li-Ca electrolyte (orange solid line) and reference samples of metallic Ca (purple dash line), CaTFSA $_{2}$ salt (green dash line) and $\mathrm{CaF}_{2}$ (blue dash line). In the light of the reference SXES spectra, we found that the oxidization of $\mathrm{Ca}^{0}$ to $\mathrm{Ca}^{2+}$ was inclined to increase the X-ray emission intensity of the Ca peaks and the relative intensity of the L2-M1 peak to the L3-M1 peak. This similar tendency was also reported for $\mathrm{Zn}^{38}$ and $\mathrm{Fe}^{39}$. Since the Ca SXES spectrum of the electrodeposits is close to that of the CaTFSA 2 , it can be concluded that the Ca signal detected by SXES and EDX (and also disappearance of diffraction from Ca metal in XRD profile) can be originated not from reduced Ca metal but from the Ca salt and/or its relevant chemical species involved in electrodepositing. Besides, in Figure 2j, the SXES result of Na K-L2 peak in the electrodeposits in the $\mathrm{Na}$-Ca electrolyte is clearly identified to the metallic state $\left(\mathrm{Na}^{0}\right)$, being consistent with the XRD results in Figure 2f. Incidentally, the Ca SXES spectra in the NaCa case is not provided because the deposited $\mathrm{Na}$ metal (melting point $\sim 98{ }^{\circ} \mathrm{C}$ ) cannot endure long time measurement under electron irradiation for detecting the slight amount of Ca component.

Reaction kinetics of the alkali metal electrodepositions. The non-dendritic morphology of alkali metals obtained in the dual-cation electrolytes would be attributed to change in the reaction kinetics caused by adding the Ca salt. To evaluate the reaction kinetics, we compare the cyclic voltammograms (CVs) in various single-cation and dualcation electrolytes. In the present CV measurements, we dared to employ the "Li RE" (illustrated in Figure 1a) for all the cases to compare the potentials in different electrolytes. The potential was scanned in a range of $-1 \mathrm{~V} \sim 1 \mathrm{~V}$ vs. Li RE at a scan rate of $10 \mathrm{mV} \mathrm{s}^{-1}$.

Figure 3a shows the CV profile in the Ca electrolyte. The response current density was almost zero on a $\mathrm{Cu}$ foil, which indicates the $\mathrm{Ca}^{2+} /$ Ca redox reaction can hardly occur. This is consistent with the result on the constant potential electrodeposition as show in the inset in Figure 1b. Next, to investigate how the additive Ca salt affects not only cathodic but also anodic reactions, Li-foil WE was used for the CV tests in the Li or Li-Ca electrolyte and similarly Na-foil WE was used for the tests in the Na or Na-Ca electrolyte. In the single-cation Li or Na electrolyte (Figures $\mathbf{3 b}$ and $\mathbf{3 c}$ ), the response current is substantially proportional to the scanning potential, displaying a symmetry reaction both in the cathodic and anodic ranges. In contrast, in the dual-cation (Li-Ca and Na-Ca) electrolytes (Figures $\mathbf{3 d}$ and $\mathbf{3 e}$ ), the slopes of the cathodic currents are obviously decreased, whereas those of the anodic currents remain unchanged. Since the equilibrium redox potentials (where response current becomes zero) of $\mathrm{Li}^{+} / \mathrm{Li}$ and $\mathrm{Na}^{+} / \mathrm{Na}$ are substantially unchanged in the $\mathrm{Li}$ and Li-Ca electrolytes and also in the Na and Na-Ca electrolytes, respectively, the addition of Ca salt mainly affects the kinetic aspect of the redox reaction. Similar results are also observed in CVs using a $\mathrm{Cu}$ foil $\mathrm{WE}$, where the coulombic efficiency of Li and $\mathrm{Na}$ electrodepositions are improved owing to the dendrite-free morphology achieved in the dual-cation electrolytes; see Figure S3.
Moreover, as shown in Figures $\mathbf{3 f}$ and $\mathbf{3 g}$, the chronopotentiometry experiments using $\mathrm{Li}-\mathrm{Li}$ symmetric cells also proved that adding $\mathrm{CaTFSA}_{2}$ salt could remarkably improve the cycle life and moderate the overvoltage increasing during cycles. Nevertheless, since the abrupt short circuit occurs due to the depletion of the $\mathrm{Ca}^{2+}$ content in the electrolyte upon cycles, this involvement must be overcome in a future work; details are given in Figure $\mathbf{S 4}$.

Generally, it is known that the electrodeposition process can be divided into the following three steps ${ }^{17,40-42}$ : (i) Cations are transported from the bulk electrolyte to the electrode. (ii) Cations are desolvated from the coordinating solvent molecules and anions and then reduced to atoms by the electrons coming from the electrode. (iii) Reduced atoms are absorbed on the electrode surface to form crystals. It may be considered that the current density in the CV profiles, Figures $3 b-3 e$, is mainly dominated by the steps (i) and (ii). The step (iii) would not markedly affect the redox reactions because Li or Na metal foil was used as WE, where the nucleation processes is not necessary (just only growth/adhesive process is required). In the $\mathrm{Li}$ or $\mathrm{Na}$ single-cation electrolyte (Figure 3b and 3c), the step (i) can be the ratedetermining process, where their desolvation kinetics is sufficiently fast in terms of the diffusion in the electrolyte. In this situation, a steep gradient of concentration would be generated towards the electrode surface (where carrier cations are dried up), leading to the dendritic growth during the crystallization ${ }^{17}$. The non-uniform crystallization would further lead to a non-uniform electric field that further accelerates the dendritic growth. In contrast, the decrease in the cathodic current densities in the Li-Ca and Na-Ca dualcation electrolytes (Figures $3 \mathrm{c}$ and $3 \mathrm{e}$ ) implies that the additive Ca salt raises the activation energy of the electrodepositions. This would be mainly ascribed to the changes in desolvation kinetics with charge transfer processes in the step (ii).

Here we try to grasp the effects of adding Ca cation, focusing on the solvation structures in the dual-cation electrolytes. Figures $\mathbf{3 h}$ and $\mathbf{3 i}$ show the experimental Raman spectra of the $\mathrm{Li}, \mathrm{Ca}, \mathrm{Li}-\mathrm{Ca}$ and $\mathrm{Na}, \mathrm{Ca}, \mathrm{Na}-\mathrm{Ca}$ electrolytes, respectively. The Raman peak around $740 \sim 750 \mathrm{~cm}^{-1}$ is attributed to expansion and contraction of the whole TFSAanion $^{43}$. The peak intensity increases as the salt concentration increases, showing a very slight rise in the wavenumber (Figure S5), being consistent with the previous report. $^{44}$ On the other hand, the Raman peaks around $770 \sim 900 \mathrm{~cm}^{-1}$ is attributed to the vibration of G3 molecule. Especially, the Raman peaks around $870 \sim 880 \mathrm{~cm}^{-1}$ can be assigned to a characteristic $\mathrm{C}-\mathrm{O}-\mathrm{C}$ stretching and $\mathrm{H}-\mathrm{C}-\mathrm{H}$ rocking vibration mode when the chain-like ether molecules chelate metal cations, which is usually called "breathing mode" 44,45 . For certain ether and cation species, the frequency of the breathing mode depends on the coordination number and the chelation configuration. The breathing modes in the single-cation $\mathrm{Li}, \mathrm{Na}$, and $\mathrm{Ca}$ electrolytes are almost unchanged in the present concentration range $0.1 \sim 1.0$ $\mathrm{mol} \mathrm{L}^{-1}$ (see Figure S5). The peaks assigned to the breathing mode in the respective single-cation electrolytes are indicated by colored vertical lines. Interestingly, compared to 
a
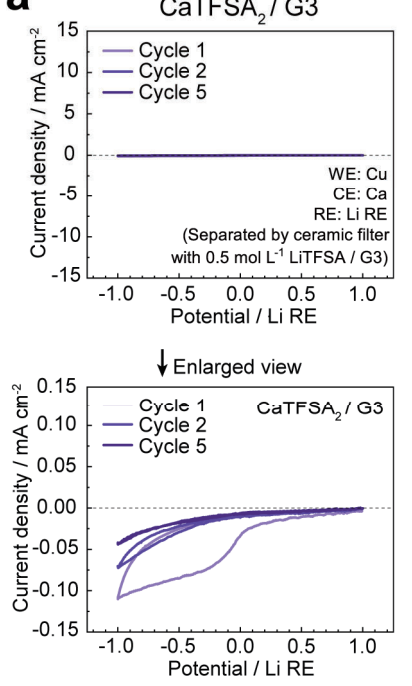

b
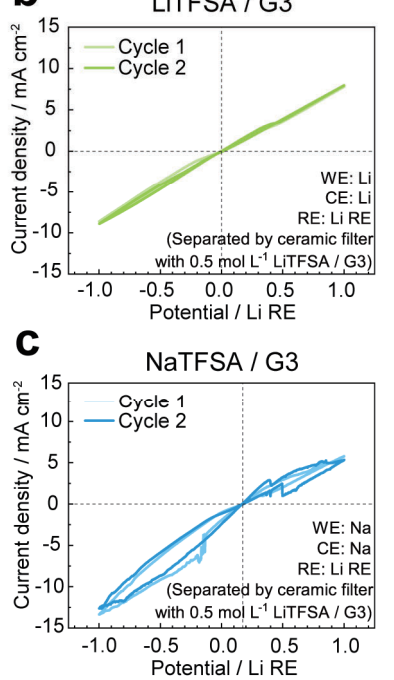

d

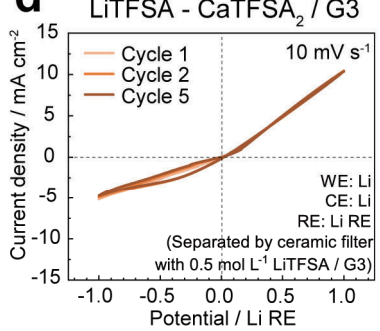

e NaTFSA-CaTFSA $/$ G 3

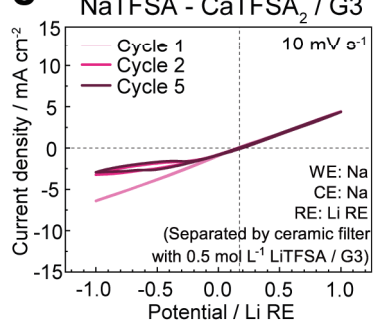

f

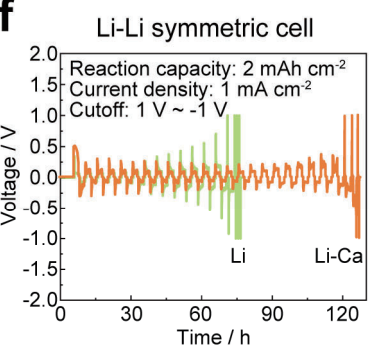

g

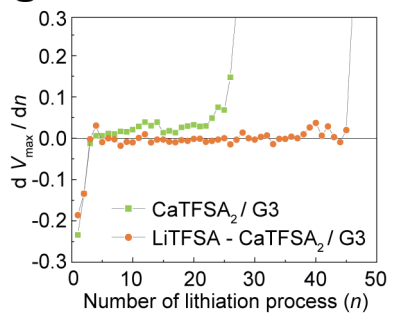

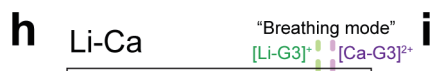

i Na-Ca $\begin{gathered}\text { "Breathing mode" } \\ \left.[\mathrm{Na}-\mathrm{G} 3]^{10}\right]^{4}[\mathrm{Ca}-\mathrm{G} 3]^{2}\end{gathered}$
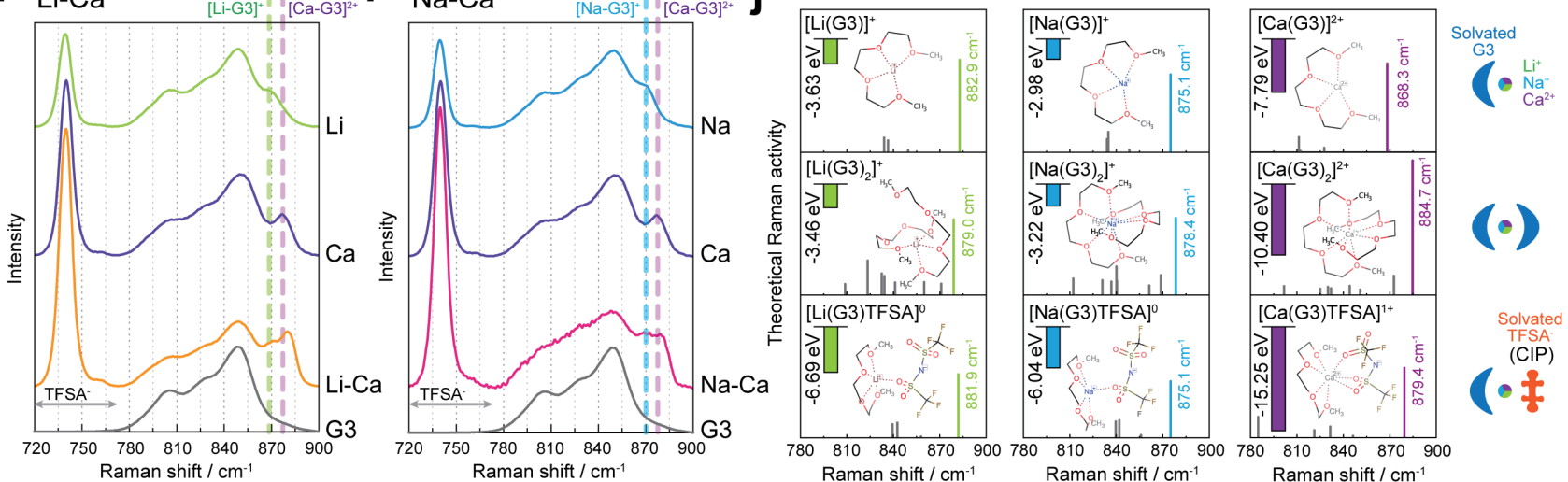

Figure 3. Cyclic voltammograms (CVs), Raman spectra in various electrolytes, and Gaussian calculation for Raman shift. CVs profiles obtained for (a) CaTFSA /G3, (b) LiTFSA/G3, (c) NaTFSA/G3, (d) LiTFSA-CaTFSA /G3, (e) $\mathrm{NaTFSA}_{2}-\mathrm{CaTFSA}_{2} / \mathrm{G} 3$. Cu foil was used as the working electrode (WE) in (a), Li and Na foil were employed as WE in (b, c) and (d, e), respectively. For the reference electrode, Li reference electrode (Li RE) was used, where Li foil was immersed in LiTFSA/G3 and separated from the electrolyte by a ceramic filter, as illustrated in Figure 1(a). (f) Galvanostatic deposition/dissolution profiles for Li-Li symmetric cells with the Li electrolyte (green) and with the Li-Ca electrolyte (orange). (g) Maximum voltage change ratio with respect to the number of the lithiation processes $(n) ; n$ is double of the cycle number because of the symmetric cell structure. Each salt concentration in all the electrolyte was $0.5 \mathrm{~mol} \mathrm{~L}^{-1}$. Experimental Raman spectra of (h) the Li, $\mathrm{Ca}$, Li-Ca electrolytes and (i) the $\mathrm{Na}, \mathrm{Ca}$, $\mathrm{Na}$-Ca electrolytes in the range of 720 $900 \mathrm{~cm}^{-1}$. (j) Raman shifts and activities of $\mathrm{Li}^{+}-\mathrm{G} 3, \mathrm{Na}^{+}-\mathrm{G} 3, \mathrm{Ca}^{2+-} \mathrm{G} 3$ complexes around 780-900 $\mathrm{cm}^{-1}$ computed with density functional theory (DFT) methods of B3LYP/6-311++ $\mathrm{G}(d, p)$ using Gaussian 16 code ${ }^{48}$. Also the formation energies of various $\mathrm{Li}^{+}, \mathrm{Na}^{+}$complexes computed by B3LYP $/ 6-311^{++} \mathrm{G}(d, p)$ are shown. The binding energy would significantly increase if a TFSA- anion is directly coordinated to a $\mathrm{Li}^{+}, \mathrm{Na}^{+}$cation in CIP state. The structures of the complexes are illustrated based on the computational results. The characteristic "breathing mode" of G3 molecule is colored in each case, which is generated when the G3 molecule chelate a cation. The Raman shifts of the breathing mode increase in the dual-cation electrolytes as shown in (h) and (i), indicating the changes of chelated G3 molecules. Note that theoretical and experimental Raman spectra can be discussed qualitatively but the values cannot be compared directly.

the single-cation electrolytes, the breathing mode especially related to $\mathrm{Ca}^{2+}$ is obviously shifted to high frequency in both the Li-Ca and Na-Ca dual-cation electrolytes.

This Raman spectroscopy measurement indicates that the solvation structure in the dual-cation electrolytes is modified by adding CaTFSA $A_{2}$, which significantly affects the reaction kinetics upon the electrodeposition. Then, we try to understand the shift of the breathing mode with the aid of computation. Figure $3 \mathbf{j}$ shows the theoretical Raman activities of G3 vibration in various complexes computed by the density functional theory (DFT) methods at the B3LYP $/ 6-311^{++} \mathrm{G}(d, p)$ level using Gaussian 16 code $^{48}$. It is found that the frequency of the breathing mode is affected by the coordination number of G3. Most importantly, for the 
$\mathrm{Ca}^{2+}-\mathrm{G} 3$ complex, the Raman shift to a higher frequency (c.a. $2 \%$ ) can be observed for $\left[\mathrm{Ca}(\mathrm{G} 3)_{2}\right]^{+}$compared to $[\mathrm{Ca}(\mathrm{G} 3)]^{2+}$, indicating that the breathing mode would be enhanced when the chelated G3 molecule is increased. As to the G3 coordinated to $\mathrm{Li}^{+}$or $\mathrm{Na}^{+}$, the frequencies are substantially unchanged (within 1\%) without respect to the coordination number of G3. Rather, the breathing mode of $\left[\mathrm{Li}(\mathrm{G} 3)_{2}\right]^{+}$ shows a lower frequency (green) than that of [Li(G3) $]^{+}$, that is, the Raman shift of breathing mode decreases when the chelated G3 molecule is increased. The different tendency of $\mathrm{Li}^{+}$compared to $\mathrm{Na}^{+}$and $\mathrm{Ca}^{2+}$ would be originated from the difference in the ionic radii ${ }^{46}$. As shown in the inset in Figure $3 \mathrm{j}$, the smaller $\mathrm{Li}^{+}$cation cannot be coordinated by all of the 8 oxygens of two G3 molecules in the [Li(G3) $]^{+}$complex, and the repulsion between oxygens weakens the breathing mode. Furthermore, also in the cases of CIPs such as Li(G3)TFSA and $\mathrm{Na}(\mathrm{G} 3)$ TFSA complexes, although few changes are seen in their breathing-mode frequencies related to G3, the binding energies of Li(G3)TFSA and $\mathrm{Na}$ (G3)TFSA are about two times higher than [Li(G3) $\left.{ }_{2}\right]^{+}$and $\left[\mathrm{Na}(\mathrm{G} 3)_{2}\right]^{+}$, indicating that the CIP state causes stronger solvation bonds with alkali cations in the dual-cation electrolytes. Therefore, if such a CIP state is preferred in the dual-cation electrolyte, the entropic disadvantage accompanying the CIP formation would be compensated by the ionized dissolution of the divalent Ca cations and TFSA anions.

Molecular dynamics simulations of dual-cation electrolytes. The above calculation provides the useful information on the static coordinate of G3 and TFSA around one cation. However, it is quite significant to investigate whether the CIP states, such as Li(G3)TFSA and $\mathrm{Na}(\mathrm{G} 3) \mathrm{TFSA}$, actually occur in the more practical situation or environment. Thus, to further understand the solvation structure, we performed molecular dynamics (MD) simulations in series of the electrolytes consisting of G3 solvent with different TFSA- salts; e.g., the solution model of $0.5 \mathrm{~mol}$ $\mathrm{L}^{-1}$ LiTFSA/G3 consists of $10 \mathrm{Li}^{+}, 10$ TFSA and $111 \mathrm{G} 3$. Details of the calculations are described in Methods.

Figures $\mathbf{4 a}$ and $\mathbf{4 b}$ show the computed coordination numbers in single-cation electrolytes of alkali metals (Li, $\mathrm{Na}$, $\mathrm{K}, \mathrm{Cs}$ ) and in single-cation electrolytes of alkaline earth metals ( $\mathrm{Mg}, \mathrm{Ca}, \mathrm{Ba})$, respectively. The coordination numbers of G3 solvent and TFSA anion were estimated based on the number of oxygen atoms nearest to the cation (i.e., in the first solvation shell). For example, if the number of oxygen atoms belonging to $\mathrm{G}_{3}\left(\mathrm{C}_{8} \mathrm{H}_{10} \mathrm{O}_{4}\right)$ or TFSA- $\left(\left[\mathrm{N}\left(\mathrm{SO}_{2} \mathrm{CF}_{3}\right)_{2}\right]^{-}\right)$in the first solvation shell is 4 , the coordination number would be counted as $1(=4 / 4)$ because each molecule has 4 oxygen atoms. The partial distribution functions of the oxygen around cations are shown in Figure S6. TFSA- anions chelating to the cations in the first solvation shell can be assigned as contact ion pair (CIP) state. Other TFSA- anions, which are separated from the cations by the G3 solvent, can be regarded as the solvent-separated ion pair (SSIP) state. In the single-cation electrolyte, the alkali cations are shown to be primarily coordinated by G3 molecules, and the coordination numbers increase according as the ionic radii $\left(\mathrm{Li}^{+}\right.$ $\left.<\mathrm{Na}^{+}<\mathrm{K}^{+}<\mathrm{Cs}^{+}\right)$regardless of the salt concentration $(0.1 \sim$ $1.0 \mathrm{~mol} \mathrm{~L}^{-1}$ ). The TFSA anions are almost in the SSIP state, indicating week combination with the alkali cations. In contrast, the alkaline earth cations $\left(\mathrm{Mg}^{2+}, \mathrm{Ca}^{2+}, \mathrm{Ba}^{2+}\right)$ tend to be directly combined with TFSA ${ }^{-}$anion (CIP state), especially when the salt concentrations are increased. This marked difference in these combination states would originate from the relatively strong coulomb interactions of the divalent cations.

On the other hand, in the Li-Ca and Na-Ca dual-cation electrolytes, the solvation structures of $\mathrm{Li}^{+}$and $\mathrm{Na}^{+}$cations are remarkably changed. Figure $\mathbf{4 c}$ show the change in the coordination numbers for $\mathrm{Li}-\mathrm{Ca}$ and Na-Ca electrolytes, as a function of the content of $\mathrm{CaTFSA}_{2}$, that is added into the solution model of $0.5 \mathrm{~mol} \mathrm{~L}^{-1}$ LiTFSA/G3 or NaTFSA/G3. Corresponding partial distribution function profiles are provided in Figures S7 and S8. Interestingly, adding the CaT$\mathrm{FSA}_{2}$ salt significantly promote the coordination of TFSA anions to the $\mathrm{Li}^{+}$and $\mathrm{Na}^{+}$cations. Especially for the dual-cation electrolytes with $0.4 \mathrm{~mol} \mathrm{~L}^{-1} \mathrm{CaTFSA}_{2}$, the coordination number of TFSA- to $\mathrm{Li}^{+}$or $\mathrm{Na}^{+}$cation reaches about 0.5 , which means that two of the four oxygens of a TFSA- anion chelate $\mathrm{a} \mathrm{Li}^{+}$and $\mathrm{Na}^{+}$cation on average.

Based on the simulation results, the additive CaTFSA $\mathrm{C}_{2}$ is found to modify the solvation structure of the alkali cation to be chelated by the TFSA- anions directly rather than by the G3 molecules, thus getting closer to contact ion pair "CIP" state from solvate-separated ion pair "SSIP" state. Figures $\mathbf{4 d}$ and $\mathbf{4 e}$ shows several typical solvation structures of $\mathrm{Li}^{+}$ and $\mathrm{Na}^{+}$extracted from the snapshots (in the Li-Ca or Na-Ca electrolyte) during the MD simulations (enlarged views given in Figure S9 and S10). The coordination numbers (c.n.) of G3 and TFSA counted from the number of the nearest oxygen atoms are also shown below the figures. Adding CaTFSA $_{2}$ increases the fraction of the CIP complexes (alkali cation coordinated by both G3 and TFSA') and reduces that of the SSIP complexes (alkali cation coordinated by G3 without TFSA'). This result is in very good agreement with the Gaussian calculation shown in Figure 3j. Besides, the similar solvation structures are also obtained in the MD simulation for the models of Li-Mg and Li-Ba dual-cation electrolytes, suggesting the universality of the dual-cation effects; see Figure S11 and S12. Direct coordinating of TFSA- to alkali cation increases markedly the solvation energy, as shown in Figure 3j, which can well explain the current-density decrease observed in CVs of Figure $3 \mathrm{c}$ and $3 \mathrm{e}$.

We here speculate why such a CIP state of alkali cation is preferred in the dual-cation electrolyte from the viewpoint of the inter-cation distances. As shown in Figures $\mathbf{4 f}$ and $\mathbf{4 g}$, the partial radial distribution functions, $\rho g(r)$, on $\mathrm{Li}^{+}-\mathrm{Li}^{+}$and $\mathrm{Na}^{+}-\mathrm{Na}^{+}$, indicate that their inter-cation distances in the dual cation electrolytes are dramatically shortened compared to those in the single-cation electrolyte. This reflects that the electrostatic interaction between the alkali cations is diminished or alleviated by the more electrically neutral CIP state with TFSA- Furthermore, such $\mathrm{Li}^{+}$and $\mathrm{Na}^{+}$cations in the CIP state tend to interpose among the $\mathrm{Ca}^{2+}$ cations (compare purple dashed and solid curves in Figures $\mathbf{4 h}$ and $\mathbf{4 i}$ ), which would contribute to reducing the total free energy of the solution systems and, especially, to separating the divalent $\mathrm{Ca}$ cations distantly. 
a
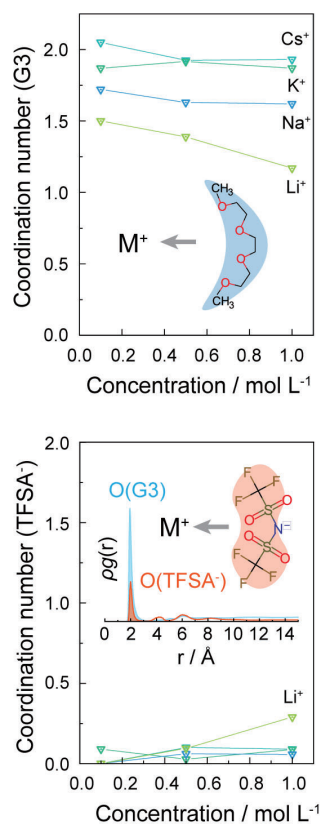

f

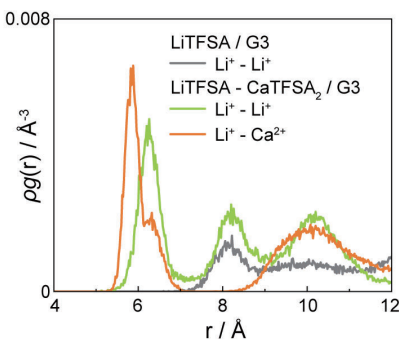

g

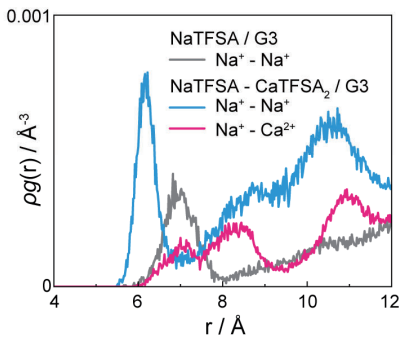

b Alkaline earth metal salts
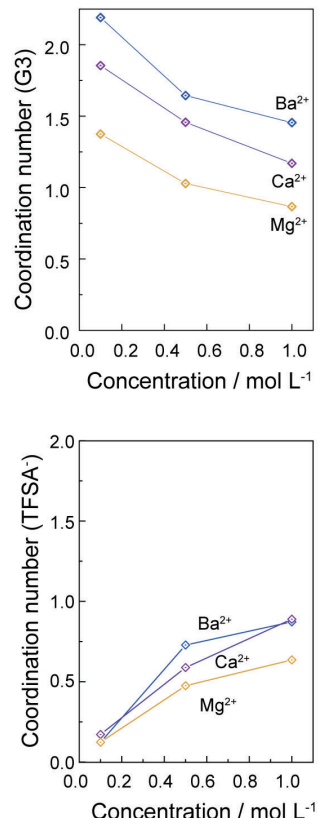

C Dual-cation $\mathrm{Li}-\mathrm{Ca}$ and $\mathrm{Na}-\mathrm{Ca}$
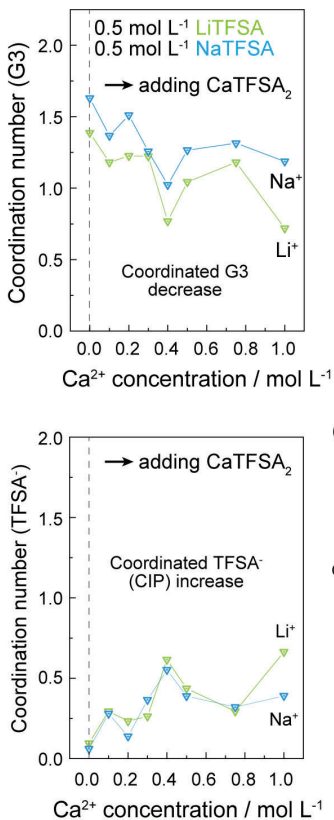

d Li-Ca dual-cation electrolyte
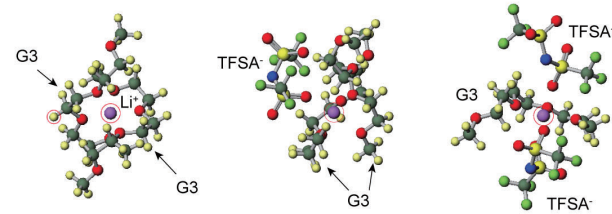

$\left[\mathrm{Li}(\mathrm{G} 3)_{2} \mathrm{TFSA}^{0}\right.$

G3 c.n. (5/4) 1.25

G3 c.n. $(6 / 4) \sim 1.5$

TFSA c.n. $(0 / 4) \sim 0$

TFSA c.n. (1/4) $\sim 0.25$

TFSA c.n. (2/4) 0.

oxygen chelating to $\mathrm{Li}^{+}$

e Na-Ca dual-cation electrolyte

Total oxygen c.n. to $\mathrm{Na}^{+} \sim 7$
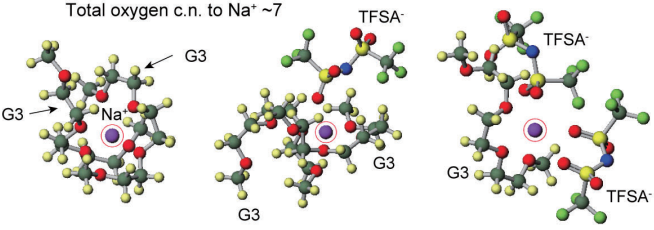

$\left[\mathrm{Na}(\mathrm{G} 3)_{2}\right]^{+}$

G3 c.n. (7/4) 1.75 G3 c.n. (6/4) 1.50

[Na(G3)TFSA $\left.{ }_{2}\right]$

G3 c.n. (3/4) $\sim .75$ TFSA c.n. (4/4) 1
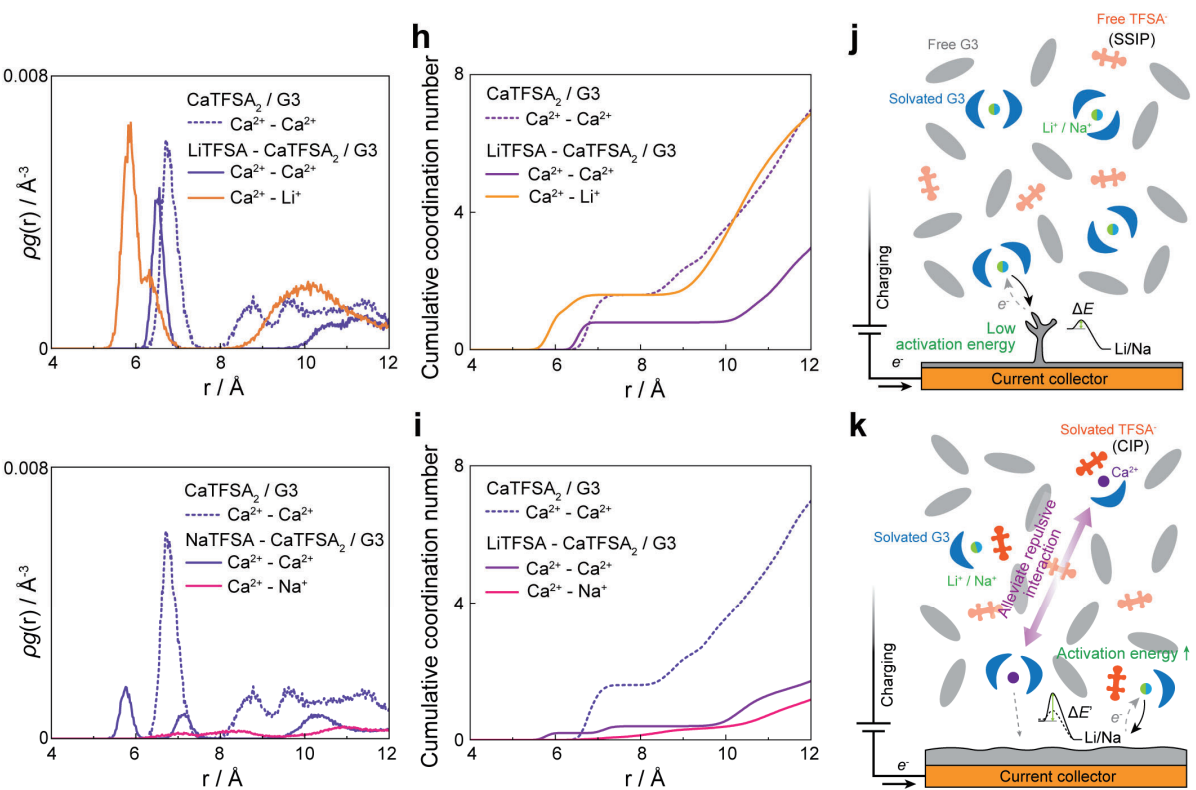

Figure 4. Coordination number, solvation structure in dual-cation electrolytes, and mechanism of electrodeposition process computed by molecular dynamics (MD) simulations. Coordination numbers for (a) alkali metal (Li, Na, K, Cs) single-cation electrolytes, (b) alkaline earth metal (Mg, Ca, Ba) single-cation electrolytes, and (c) Li-Ca and Na-Ca dual-cation electrolytes. Coordination numbers in the first solvation shell of the cations were evaluated based on the nearest-neighbor oxygen atoms belonging to the G3 molecule and TFSA anion. CaTFSA 2 was gradually added into the solution models of $0.5 \mathrm{~mol} \mathrm{~L}^{-1} \mathrm{LiTFSA} / \mathrm{G} 3$ and NaTFSA/G3. In singlecation electrolytes, alkali cations are almost coordinated by G3 molecule, whereas the alkaline earth cations are preferred to be partially coordinated by the TFSA- anions with an increase in the concentration. In the dual-cation cases, TFSA- coordinated to $\mathrm{Li}^{+}$ and $\mathrm{Na}^{+}$(conduct ion pair, CIP) is remarkably increased. Solvation structure in (d) Li-Ca and (e) Na-Ca dual-cation electrolytes, extracted from a typical snapshot during the MD simulations. Coordination numbers (c.n.) of G3 and TFSA- based on the nearest oxygen atoms to the cations are also shown below each figure. Cation-cation partial distribution functions, $\rho g(r)$, in (f) the Li, Li-Ca electrolytes and (g) the $\mathrm{Na}$, Na-Ca electrolytes, and corresponding cumulative coordination numbers calculated from $\rho g(r)$ are shown in (h) and (i), respectively. The CIP-state $\mathrm{Li}^{+}$and $\mathrm{Na}^{+}$is shown to separate $\mathrm{Ca}^{2+}$ ions distantly in the dual-cation electrolytes. Electrodeposition mechanism in ( $\mathrm{j}$ ) the $\mathrm{Li}$, Na single-cation electrolytes and (k) the $\mathrm{Li}$-Ca, $\mathrm{Na}$-Ca dual-cation electrolytes. The solvation structure of alkali cation $\left(\mathrm{Li}^{+}\right.$or $\left.\mathrm{Na}^{+}\right)$is modified to CIP by additive CaTFSA 2 in the dual-cation electrolytes, so that the desolvation energy is inevitably increased, resulting in occurrence of the electrodeposition in a reaction-limited condition. 
Table 1. Summary of additive effects of alkaline earth (Mg, Ca, Ba) TFSA salts on the alkali-metal (Li, Na) electrodeposition in TFSA-/G3 electrolytes consisting of single cation or dual cations.

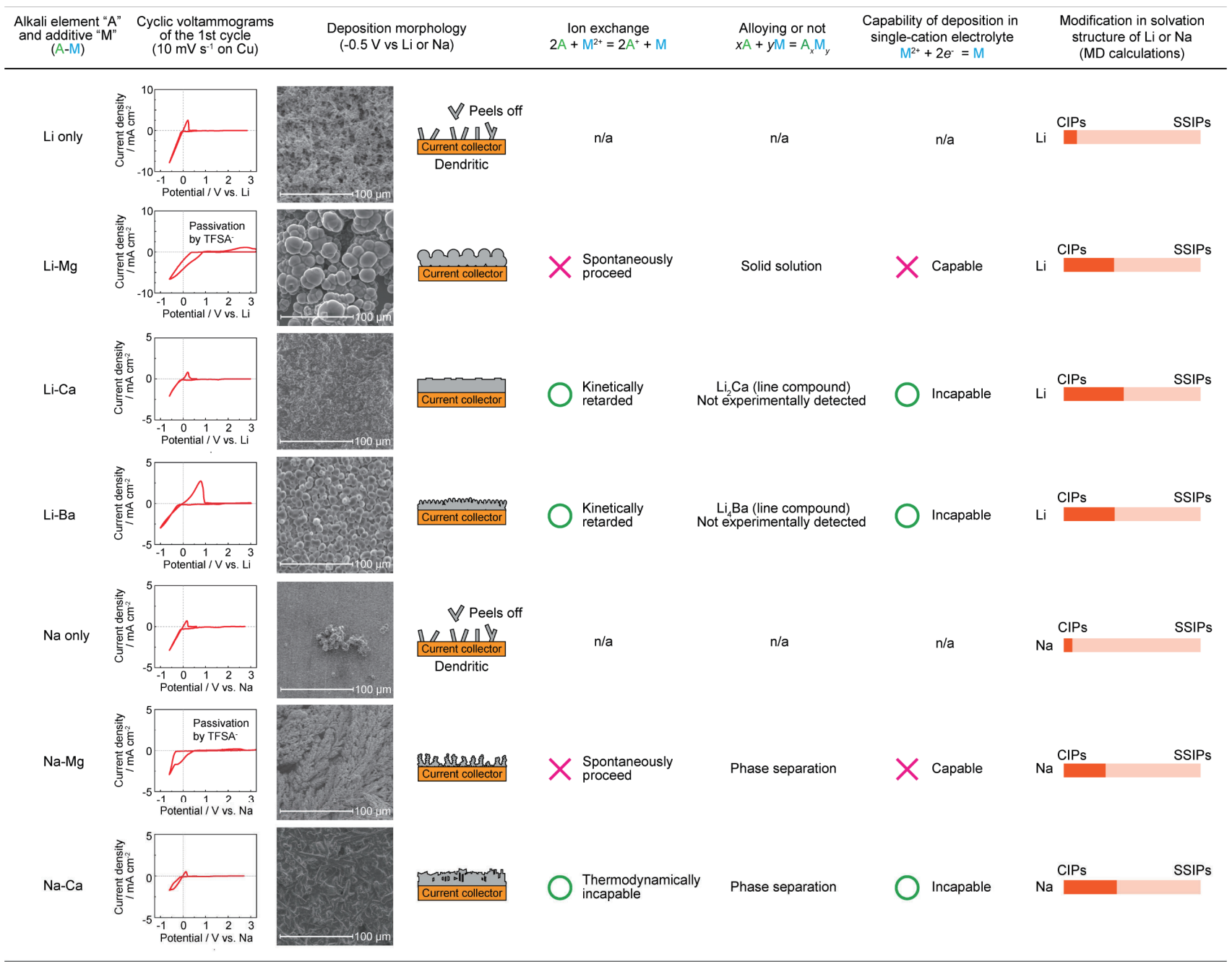

"A" denotes Li or $\mathrm{Na}$, and "M" denotes the alkaline earth element of $\mathrm{Mg}$, Ca, or Ba. The CV measurements and constant potential electrodepositions were done in various electrolytes, where each salt was set to $0.5 \mathrm{~mol} \mathrm{~L}^{-1}$ in the respective electrolytes. The column for "Modification in solvation structure" shows the ratios of the contact ion pairs (CIPs) to the solvent-separated ion pairs (SSIPs) of $\mathrm{Li}^{+}$or $\mathrm{Na}^{+}$, which are evaluated based on the MD results. The electrolyte models used in the MD computations consisted of the salts corresponding to the present experiments, where each concentration was set to $0.5 \mathrm{~mol} \mathrm{~L}^{-1}$. The circle and the cross marks indicate whether the characteristic is favorable (circle) or unfavorable (cross) for alkali-metal-anode batteries.

On the basis of the results on $\rho g(r)$, Figures $4 \mathbf{j}$ and $4 \mathbf{k}$ illustrate the electrodeposition mechanisms for single-cation and dual-cation electrolytes, respectively. In the single-cation electrolyte, $\mathrm{Li}^{+}$or $\mathrm{Na}^{+}$cations are almost coordinated by G3 molecules. The relatively weak solvation structure would lead to a low activation energy for the reduction reaction, so that the electrodeposition process eventually proceeds under a diffusion-limited condition. On the contrary, in the dual-cation electrolytes, the TFSA- anions tend to be closely coordinated to $\mathrm{Li}^{+}$or $\mathrm{Na}^{+}$, being in the CIP state, which would play a significant role to alleviate the strong repulsive interaction between the divalent Ca cations, as illustrated in Figure 4k. Such contact ion pairs of alkali cation and anion contribute to the high activation energy for the reduction reaction, that is, the freedom of the alkali cations is deprived by anions closely contacting to them, resultingly retarding the reduction/desolvation process. Consequently, the electrodeposition can proceed in a reaction-limited condition, which is required for realizing the dendrite-free morphology in metal anodes.

Universality of divalent cation mixing effects. Besides the Ca salts, other alkaline earth divalent cations can also be intriguing candidates that provide similar effects in modifying the solvation structure of alkali cations. In order to establish general rules for the electrolyte design, we summarize the additive effects of alkaline earth salts of $\mathrm{MgTFSA}_{2}$, $\mathrm{CaTFSA}_{2}$ and $\mathrm{BaTFSA}_{2}$ in the electrodeposition of alkali metal (Li, Na) in Table 1. The electrodeposition morphologies observed by FE-SEM are taken also from Figure S13. 
Several features to be considered for electrodeposition in dual-cation electrolyte are chosen in terms of "coulombic efficiency" from CVs, "ion exchange", "alloying capability in the phase diagram", and "electrodeposition capability of the alkaline earth cations". Further importantly, the population of CIP and SSIP evaluated from the MD simulations are listed. First of all, from the viewpoint of the solvation-structure modification, all the alkaline earth cations $(\mathrm{Mg}, \mathrm{Ca}, \mathrm{Ba})$ are suitable to form the CIP state of both the alkali cations $(\mathrm{Li}, \mathrm{Na})$. As expected, under the constant potential condition $(-0.5 \mathrm{~V}$ vs $\mathrm{Li}$ or $\mathrm{Na})$, in all the dual-cation cases the electrodeposits are found to exhibit morphologies distinct from the conventional dendritic one (of Li or $\mathrm{Na}$ ). Specifically, among them, $\mathrm{Li}-\mathrm{Ca}$, $\mathrm{Li}-\mathrm{Ba}$, and $\mathrm{Na}-\mathrm{Ca}$ systems are preferred in terms of the single alkali-cation electrodeposition.

In the $\mathrm{Li}-\mathrm{Mg}^{31}$ and $\mathrm{Na}-\mathrm{Mg}$ electrolytes, the electrodeposits also contain Mg in a ball-like shape without dendrites, because Mg metal is capable to be plated in the Mg single-cation electrolyte. Especially, in the bulk amount of electrolyte, $\mathrm{Li}$ or $\mathrm{Na}$ atoms in the deposit are spontaneously replaced by $\mathrm{Mg}^{2+}$ cations remaining due to the higher redox potential of $\mathrm{Mg}^{2+} / \mathrm{Mg}$ (about $0.7 \mathrm{~V}$ vs $\mathrm{Li}, 0.3 \mathrm{~V}$ vs $\mathrm{Na}$ ). In contrast, $\mathrm{Ca}^{2+}$ and $\mathrm{Ba}^{2+}$ cannot be plated in the single-cation electrolytes, although they exhibit the redox potentials very close to $\mathrm{Li}$ and $\mathrm{Na}\left(\mathrm{Ca}^{2+} / \mathrm{Ca}\right.$ is $0.18 \mathrm{~V}$ vs $\mathrm{Li},-0.13 \mathrm{~V}$ vs $\mathrm{Na}$, and $\mathrm{Ba}^{2+} / \mathrm{Ba}$ is $0.06 \mathrm{~V}$ vs Li). As a result, the chemical composition of the electrodeposits is not significantly affected by the additive salts. In these cases, the additive cations could work as a solvation structure modifier to circumvent the dendritic growth of alkali metals. Overall, for constructing dual-cation electrolyte systems towards dendrite-free alkali-metal anodes, an effective additive salt should have the following three characteristic features: (i) to moderate the desolvation process of alkali cations, (ii) to prevent the ion exchange and the reduction from the electrolyte, and (iii) not to interfere the dissolution process of the deposited alkali metal.

\section{- SUMMARY AND PRESPECTIVES}

Grasping and solving of the fatal "dendritic growth" problems are indispensable for practical use of alkali metal anodes in rechargeable batteries. Complicated reactions occurring between organic electrolytes and metal anodes make it difficult to ascertain the key factor determining the electrodeposition morphology. In this work, we revealed that mixing of divalent cations $\left(\mathrm{Ca}^{2+}\right)$ with monovalent cations $\left(\mathrm{Li}^{+}\right.$or $\left.\mathrm{Na}^{+}\right)$can significantly modify the solvation environment in the electrolytes (altering from SSIP to CIP of alkali cations), which helps the electrodeposition of $\mathrm{Li}$ or $\mathrm{Na}$ metal keep in a reaction-limited process. This feature of the solvation change contributes to making uniform diffusion field around the electrode surface, providing a recipe towards a long-awaited flat deposition morphology. Although we still have a problem on the coulombic efficiency in the dual-cation electrolytes, our present study significantly advances with unveiling the reaction mechanism of metal anodes and provides design guidelines for future dual-cation electrolytes towards developing safe and high-performance rechargeable batteries.

\section{- EXPERIMENTAL SECTION}

Materials preparation. Bis(trifluoromethanesulfonyl)imide, TFSA', salts (purity 99.5\%) were purchased from SOLVIONIC Company and Kishida Chemical Co., Ltd. Triethylene Glycol Dimethyl Ether, G3, solvent (purity $>99.0 \%$ ) was purchased from Tokyo Chemical Industry Co., Ltd. The electrolytes with various salt concentrations were prepared in gloveboxes (Miwa Mfg Co., Ltd. and UNICO Ltd.) filled with high purity argon atmosphere. For the counter and reference electrodes, sodium and calcium metals were purchased from Sigma-Aldrich Co. LLC., and lithium metal was purchased from Honjo Metal Co., Ltd. For the current collector (working electrodes), copper and phosphor bronze foils (thickness $20 \mu \mathrm{m}$ ) were purchased from Takeuchi Metal Foil and Powder Co., Ltd.

Electrochemical tests. Electrochemical experiments were conducted using a potentiostat VMP-3 or VSP-300 (Bio-Logic SAS). The constant potential electrodeposition was conducted with three -electrode beaker cells (VM2A, EC-frontier Co., Ltd), where the area of working electrode is fixed to be $1 \mathrm{~cm}^{-2}$. The cells were assembled and tested in gloveboxes filled with high purity argon atmosphere.

Morphology observation. Electrodeposits were washed by dropping tetrahydrofuran $(99.5 \%$, FUJIFILM Wako Pure Chemical Corporation) and subsequently dried in argon atmosphere. Photos of the electrodes were taken with a mobile phone (Sony Corporation). Microstructures of the electrodeposits were observed in detail with a Field Emission Scanning Electron Microscope (FE-SEM) JSM-7200F (JEOL Ltd.) The samples were prepared in argon atmosphere and transferred to the high vacuum chamber of FE-SEM without exposure to air. Cross section samples were prepared with a trimming cutter (CSC6, JEOL Ltd.).

X-ray diffraction (XRD). XRD patterns were measured using an automated multipurpose X-ray diffractometer (SmartLab, Rigaku Corporation). An air-tight stage was used to keep an argon atmosphere throughout the measurements without exposing samples to air.

Soft X-ray emission spectroscopy (SXES). The SXES was conducted using the spectrometers (JS300N and JS2000, JEOL Ltd.) attached on the FE-SEM. The X-ray was excited by a finely focused incident electron beam. The acceleration voltage of the electron beam was $15 \mathrm{kV}$ and the current was around $50 \mathrm{nA}$. The background of the SXES spectra was removed and the intensity was normalized with respect to the L3-M1 peak for Ca and K-L2 peak for Na. Shift in the experimental X-ray energies was corrected based on the database values ${ }^{47}$.

Composition analyses. Energy dispersive X-ray spectroscopy (EDX) detector attached on the FE-SEM was used to measure the composition of the electrodeposits. Inductively coupled plasma optical emission spectroscopy (ICPOES) and X-ray fluorescence measurements were entrusted to Analytical Research Core for Advanced Materials, Institute for Materials Research, Tohoku University.

Raman spectroscopy. The Raman spectra of the electrolytes with various concentrations was measured at room 
temperature using Raman spectrometer NRS-5100, JASCO corporation. To capable the comparison of intensity among different samples, each electrolyte was injected into a deep columnar container made of stainless steel, where the sample irradiated by the incident laser $(532 \mathrm{~nm})$ was fixed to the same volume.

First-principles calculations. Density functional Theory (DFT) calculations were conducted using Gaussian 16 code $^{48}$ with B3LYP hybrid functional ${ }^{49}$ and $6-311^{++} \mathrm{G}(d, p)$ basis set ${ }^{50-52}$. The Raman activities of vibration modes of series cation-G3 complexes were estimated by normal frequency analyses. The formation energy of each complex was calculated according to $\Delta E=E$ (complex) - $E$ (cation) - $E$ (anion) - $E$ (G3), where $E$ is the electronic energy of each species complemented with thermal free energy correction.

Molecular dynamics (MD) simulations. The MD simulations were performed with LAMMPS $\operatorname{code}^{53}$. The solution models were constructed with $111 \mathrm{G} 3$ molecules as the solvent and appropriate number of cations and TFSA anions corresponding to the proper salt concentration. For example, the model of $0.5 \mathrm{~mol} \mathrm{~L}^{-1} \mathrm{NaTFSA}-0.5 \mathrm{~mol} \mathrm{~L}^{-1} \mathrm{CaTFSA}_{2} /$ G3 electrolyte consisted of $10 \mathrm{Na}^{+}, 10 \mathrm{Ca}^{2+}$ cations, 30 TFSA anions and $111 \mathrm{G} 3$. Each model was built in a cubic box with random configuration of the species. The initial volume of each box was set according to the practical density of the corresponding electrolyte. For the force field parameters, the pair interaction potentials between the cations with TFSA ${ }^{-}$and G3, was calculated based on the Lennard-Jones (LJ) potential with the long-distance coulomb interaction (cutoff distance of $15 \AA$ ). LJ parameters for the cations were adopted from a previous work by S. Mamatkulov et $\mathrm{al}^{54}$. For the TFSA and G3, structure optimization was first conducted by DFT calculations (B3LYP/6-311 ${ }^{++} \mathrm{G}(d, p)$ at Gaussian $16^{48}$ ), and then the restrained electrostatic potential (RESP) ${ }^{55}$ was calculated to determining the partial charges. Subsequently, the force-field parameters (LJ, bond, angle, dihedral) were generated using the general AMBER force field (GAFF2) ${ }^{56,57}$. The Lorentz-Berthelot combining rules were employed to calculate the LJ potentials between cations with atoms in TFSA ${ }^{-}$and G3. The long-range forces ( $k$-space) were computed with the particle-particle particle-mesh (PPPM) ${ }^{58}$.

In the present MD simulations, NPT ensemble $(300 \mathrm{~K}, 1$ atm) was finally employed to estimate the solvation structure of each electrolyte model. Prior to this, in order to avoid divergence, the simulation was conducted in the following three steps. First, the energy minimization was performed for 20,000 steps to remove the obviously inappropriate atomic configurations (e.g., cation contacts, etc) in the initial solution models. Second, each model was computed using the NVT ensemble $(300 \mathrm{~K})$ for $2 \mathrm{~ns}$ to minimize the Helmholtz free energy. Finally, each model was computed using the NPT ensemble ( $300 \mathrm{~K}, 1 \mathrm{~atm})$ for more than 5 ns to minimize the Gibbs free energy and to obtain the thermal equilibrium structure of the system. The timestep in NVT and NPT ensembles was set to $1 \mathrm{fs}$.

For analyzing the solvation structures, the partial radial distribution function, $g_{i j}(r)$, on each cation (the center atom $i=\mathrm{Li}^{+}, \mathrm{Na}^{+}, \mathrm{Ca}^{2+}$, etc; the counter atom $j=\mathrm{Li}^{+}, \mathrm{Na}^{+}, \mathrm{Ca}^{2+}$, etc, and $\mathrm{O}^{2-}$ ) was multiplied by the number density, $\rho_{j}$, of corresponding counter atomic species $j$, to compare variations between the different electrolyte models. The value of $\rho_{j}$ was determined by the number of each species $j$ per average cell volume in the equilibrium state. The atomic configurations and cell volume in the last $2 \mathrm{~ns}$ in the NPT-MD simulations were used to obtain $g_{i j}(r)$ and $\rho_{j}$. Using $g_{i j}(\mathrm{r})$, the partial coordination number in the shell between $r_{1}$ and $r_{2}$ was calculated by the following equation,

$$
n_{i j}=\int_{r_{1}}^{r_{2}} 4 \pi r^{2} \rho_{j} g_{i j}(r) d r
$$

Figure $4 \mathrm{~h}$ and $4 \mathrm{i}$ were obtained by the integration from $r_{1}$ $=0$ to $r_{2}$, where $r_{2}$ was altered from 0 to $12 \AA$, which indicates the cumulative coordination number, $n_{i j}$, around each cation species $i$. On the other hand, using the cation-oxygen correlation $g_{i 0}(r)$, the coordination number (c.n.) of the nearest oxygen atoms around the center cation $i$ was calculated in the first solvation cell, where the shell thickness, $r_{1}$ and $r_{2}$, depends on each cation. As an example, the interval of integration used for oxygen coordinated around $\mathrm{Li}^{+}$is shown in Figure S6a. Especially, the oxygen atoms belonging to $\mathrm{G} 3\left(\mathrm{C}_{8} \mathrm{H}_{18} \mathrm{O}_{4}\right)$ and TFSA- $\left(\left[\left(\mathrm{CF}_{3} \mathrm{SO}_{2}\right)_{2} \mathrm{~N}\right]^{-}\right)$were distinguished in computing the coordination numbers. In the body text, the subscripts are eliminated for the sake of visibility, but each $g(r)$ function is clearly displayed in different color with annotation.

\section{- ASSOCIATED CONTENT}

Supporting Information. Additional electrochemical experiments such as Li-Li symmetric cells, additional Raman results, radial distribution functions obtained by MD simulations.

\section{- AUTHOR INFORMATION}

\section{Corresponding Author}

*Hongyi Li, Email: li.hongyi@tohoku.ac.jp

* Tetsu Ichitsubo, Email: tichi@tohoku.ac.jp

\section{Author Contributions}

H.L. and T. I. conceived the study. H.L. designed the research plan and conducted the computer simulations and SXES measurement. M.M. conducted the electrochemical experiments, structure, and composition analyses. H.L. and T.I. wrote the manuscript. All authors discussed the results and contributed to the manuscript.

Notes

The authors declare no competing interests.

\section{- ACKNOWLEDGMENT}

The authors thank Center for Computational Materials Science, Institute for Materials Research, Tohoku University for the use of the supercomputer "MASAMUNE-IMR" (Project number 20S0401). The authors also thank Analytical Research Core for Advanced Materials, Institute for Materials Research, Tohoku University, for conducting the ICP and XRF analyses. H.L. thank the research grant from Collaborative Research Center on Energy Materials, Institute for Materials Research, Tohoku University. This work is supported by the Grant-in-Aid for Scientific Research (S) number 18H05249 and Grant-in-Aid for 
Research Activity Start-up number 20K22461 commissioned by Japan Society for the Promotion of Science (JSPS).

\section{REFERENCES}

(1) Chu, S.; Majumdar, A., Opportunities and challenges for a sustainable energy future. Nature 2012, 488 (7411), 294-303.

(2) Larcher, D.; Tarascon, J. M., Towards greener and more sustainable batteries for electrical energy storage. Nat. Chem. 2015, 7 (1), 19-29.

(3) Xiang, J. W.; Yang, L. Y.; Yuan, L. X.; Yuan, K.; Zhang, Y.; Huang, Y. Y.; Lin, J.; Pan, F.; Huang, Y. H., Alkali-Metal Anodes: From Lab to Market. Joule 2019, 3 (10), 2334-2363.

(4) Tian, Y.; Zeng, G.; Rutt, A.; Shi, T.; Kim, H.; Wang, J.; Koettgen, J.; Sun, Y.; Ouyang, B.; Chen, T.; Lun, Z.; Rong, Z.; Persson, K.; Ceder, G., Promises and Challenges of Next-Generation "Beyond Liion" Batteries for Electric Vehicles and Grid Decarbonization. Chem. Rev. 2021, 121 (3), 1623-1669.

(5) Manthiram, A., A reflection on lithium-ion battery cathode chemistry. Nat. Commun. 2020, 11 (1), 1550.

(6) Yabuuchi, N.; Kubota, K.; Dahbi, M.; Komaba, S., Research development on sodium-ion batteries. Chem. Rev. 2014, 114 (23), 11636-82.

(7) Hosaka, T.; Kubota, K.; Hameed, A. S.; Komaba, S., Research Development on K-Ion Batteries. Chem. Rev. 2020, 120 (14), 6358-6466.

(8) Cheng, X. B.; Zhang, R.; Zhao, C. Z.; Zhang, Q., Toward Safe Lithium Metal Anode in Rechargeable Batteries: A Review. Chem. Rev. 2017, 117 (15), 10403-10473.

(9) Lin, D.; Liu, Y.; Cui, Y., Reviving the lithium metal anode for high-energy batteries. Nat. Nanotechnol. 2017, 12 (3), 194-206.

(10) Lee, B.; Paek, E.; Mitlin, D.; Lee, S. W., Sodium Metal Anodes: Emerging Solutions to Dendrite Growth. Chem. Rev. 2019, 119 (8), 5416-5460.

(11) Gunnarsdottir, A. B.; Amanchukwu, C. V.; Menkin, S.; Grey, C. P., Noninvasive In Situ NMR Study of "Dead Lithium" Formation and Lithium Corrosion in Full-Cell Lithium Metal Batteries. .J Am. Chem. Soc. 2020, 142 (49), 20814-20827.

(12) Dahn, J. R.; Zheng, T.; Liu, Y. H.; Xue, J. S., Mechanisms for Lithium Insertion in Carbonaceous Materials. Science 1995, 270 (5236), 590-593.

(13) Wada, T.; Ichitsubo, T.; Yubuta, K.; Segawa, H.; Yoshida, H.; Kato, H., Bulk-nanoporous-silicon negative electrode with extremely high cyclability for lithium-ion batteries prepared using a top-down process. Nano Lett. 2014, 14 (8), 4505-10.

(14) Li, H.; Yamaguchi, T.; Matsumoto, S.; Hoshikawa, H.; Kumagai, T.; Okamoto, N. L.; Ichitsubo, T., Circumventing huge volume strain in alloy anodes of lithium batteries. Nat. Commun. 2020, $11(1), 1584$.

(15) Liu, H.; Cheng, X. B.; Huang, J. Q.; Kaskel, S.; Chou, S. L.; Park, H. S.; Zhang, Q., Alloy Anodes for Rechargeable Alkali-Metal Batteries: Progress and Challenge. ACS Mater. Lett. 2019, 1 (2), 217-229.

(16) Xiao, J.; Li, Q. Y.; Bi, Y. J.; Cai, M.; Dunn, B.; Glossmann, T.; Liu, J.; Osaka, T.; Sugiura, R.; Wu, B. B.; Yang, J. H.; Zhang, J. G.; Whittingham, M. S., Understanding and applying coulombic efficiency in lithium metal batteries. Nat. Energy 2020, 5 (8), 561-568.

(17) Bai, P.; Li, J.; Brushett, F. R.; Bazant, M. Z., Transition of lithium growth mechanisms in liquid electrolytes. Energ. Environ. Sci. 2016, 9 (10), 3221-3229.

(18) Hagopian, A.; Doublet, M. L.; Filhol, J. S., Thermodynamic origin of dendrite growth in metal anode batteries. Energ. Environ. Sci. 2020, 13 (12), 5186-5197.

(19) Zou, P.; Sui, Y.; Zhan, H.; Wang, C.; Xin, H. L.; Cheng, H. M.; Kang, F.; Yang, C., Polymorph Evolution Mechanisms and Regulation Strategies of Lithium Metal Anode under Multiphysical Fields. Chem. Rev. 2021, 121 (10), 5986-6056.
(20) Sand, H. J. S., III. On the concentration at the electrodes in a solution, with special reference to the liberation of hydrogen by electrolysis of a mixture of copper sulphate and sulphuric acid. The London, Edinburgh, and Dublin Philosophical Magazine and Journal of Science 2010, 1 (1), 45-79.

(21) Xu, W.; Wang, J. L.; Ding, F.; Chen, X. L.; Nasybutin, E.; Zhang, Y. H.; Zhang, J. G., Lithium metal anodes for rechargeable batteries. Energ. Environ. Sci. 2014, 7 (2), 513-537.

(22) Thirumalraj, B.; Hagos, T. T.; Huang, C. J.; Teshager, M. A.; Cheng, J. H.; Su, W. N.; Hwang, B. J., Nucleation and Growth Mechanism of Lithium Metal Electroplating. J. Am. Chem. Soc. 2019, 141 (46), 18612-18623.

(23) Xu, X.; Liu, Y.; Hwang, J. Y.; Kapitanova, O. O.; Song, Z.; Sun, Y. K.; Matic, A.; Xiong, S., Role of Li - Ion Depletion on Electrode Surface: Underlying Mechanism for Electrodeposition Behavior of Lithium Metal Anode. Adv. Energy Mater. 2020, 10 (44), 2002390.

(24) Weber, R.; Genovese, M.; Louli, A. J.; Hames, S.; Martin, C.; Hill, I. G.; Dahn, J. R., Long cycle life and dendrite-free lithium morphology in anode-free lithium pouch cells enabled by a dual-salt liquid electrolyte. Nat. Energy 2019, 4 (8), 683-689.

(25) Wang, Z.; Sun, Z.; Li, J.; Shi, Y.; Sun, C.; An, B.; Cheng, H. M.; $\mathrm{Li}, \mathrm{F}$., Insights into the deposition chemistry of Li ions in nonaqueous electrolyte for stable Li anodes. Chem. Soc. Rev. 2021, 50 (5), 3178-3210.

(26) Rakov, D. A.; Chen, F.; Ferdousi, S. A.; Li, H.; Pathirana, T.; Simonov, A. N.; Howlett, P. C.; Atkin, R.; Forsyth, M., Engineering high-energy-density sodium battery anodes for improved cycling with superconcentrated ionic-liquid electrolytes. Nat. Mater. 2020, 19 (10), 1096-1101.

(27) Wen, B. H.; Deng, Z.; Tsai, P. C.; Lebens-Higgins, Z. W.; Piper, L. F. J.; Ong, S. P.; Chiang, Y. M., Ultrafast ion transport at a cathode-electrolyte interface and its strong dependence on salt solvation. Nat. Energy 2020, 5 (8), 578-586.

(28) Cao, X.; Jia, H.; Xu, W.; Zhang, J. G., Review-Localized HighConcentration Electrolytes for Lithium Batteries. J. of the Electrochem. Soc. 2021, 168 (1).

(29) Yamada, Y.; Wang, J.; Ko, S.; Watanabe, E.; Yamada, A., Advances and issues in developing salt-concentrated battery electrolytes. Nat. Energy 2019, 4 (4), 269-280.

(30) Ding, F.; Xu, W.; Graff, G. L.; Zhang, J.; Sushko, M. L.; Chen, X.; Shao, Y.; Engelhard, M. H.; Nie, Z.; Xiao, J.; Liu, X.; Sushko, P. V.; Liu, J.; Zhang, J. G., Dendrite-free lithium deposition via self-healing electrostatic shield mechanism. J. Am. Chem. Soc. 2013, 135 (11), 4450-6.

(31) Ichitsubo, T.; Okamoto, S.; Kawaguchi, T.; Kumagai, Y.; Oba, F.; Yagi, S.; Goto, N.; Doi, T.; Matsubara, E., Toward "rockingchair type" Mg-Li dual-salt batteries. J. Mater. Chem. A 2015, 3 (19), 10188-10194.

(32) Li, H. Y.; Ichitsubo, T.; Yagi, S.; Matsubara, E., Constructing metal-anode rechargeable batteries utilizing concomitant intercalation of Li-Mg dual cations into Mo6S8. J. Mater. Chem. A 2017, 5 (7), 3534-3540.

(33) Ma, J. L.; Meng, F. L.; Yu, Y.; Liu, D. P.; Yan, J. M.; Zhang, Y.; Zhang, X. B.; Jiang, Q., Prevention of dendrite growth and volume expansion to give high-performance aprotic bimetallic Li-Na alloy02 batteries. Nat. Chem. 2019, 11 (1), 64-70.

(34) Nguyen, L. H. B.; Picard, T.; Sergent, N.; Raynaud, C.; Filhol J. S.; Doublet, M. L., Investigation of alkali and alkaline earth solvation structures in tetraglyme solvent. Phys. Chem. Chem. Phys., 2021, Advance Article

(35) Ponrouch, A.; Frontera, C.; Barde, F.; Palacin, M. R., Towards a calcium-based rechargeable battery. Nat. Mater. 2016, 15 (2), 169-72.

(36) Forero-Saboya, J.; Davoisne, C.; Dedryvere, R.; Yousef, I.; Canepa, P.; Ponrouch, A., Understanding the nature of the passivation layer enabling reversible calcium plating. Energ. Environ. Sci. 2020, 13 (10), 3423-3431. 
(37) Hong, Y. S.; Li, N.; Chen, H. S.; Wang, P.; Song, W. L.; Fang, D. N., In operando observation of chemical and mechanical stability of Li and Na dendrites under quasi-zero electrochemical field. Energy Storage Mater. 2018, 11, 118-126.

(38) Antonides, E.; Sawatzky, G. A., The L2L3M4,5Coster-Kronig process in $\mathrm{Zn}$ and $\mathrm{ZnO}$ in the solid state. Journal of Physics $C$ : Solid State Physics 1976, 9 (19), L547-L552.

(39) Terauchi, M., Information of valence charge of 3d transition metal elements observed in L-emission spectra. Microscopy (Oxf) 2019, 68 (4), 330-337.

(40) Chen, L.; Zhang, H. W.; Liang, L. Y.; Liu, Z.; Qi, Y.; Lu, P.; Chen, J.; Chen, L. Q., Modulation of dendritic patterns during electrodeposition: A nonlinear phase-field model. J. Power Sources 2015, 300, 376-385.

(41) Jäckle, M.; Helmbrecht, K.; Smits, M.; Stottmeister, D.; Groß, A., Self-diffusion barriers: possible descriptors for dendrite growth in batteries? Energ. Environ. Sci. 2018, 11 (12), 3400-3407. (42) Kossel, W., Zur Theorie des Kristallwachstums. Nachr. Ges. Wiss. Göttingen Math. Phys. 1927, 134-143.

(43) Rey, I.; Johansson, P.; Lindgren, J.; Lassègues, J. C.; Grondin, J.; Servant, L., Spectroscopic and Theoretical Study of (CF3SO2)2N- (TFSI-) and (CF3SO2)2NH (HTFSI). J. Phys. Chem. A 1998, 102 (19), 3249-3258.

(44) Brouillette, D.; Irish, D. E.; Taylor, N. J.; Perron, G. r.; Odziemkowski, M.; Desnoyers, J. E., Stable solvates in solution of lithium bis(trifluoromethylsulfone)imide in glymes and other aprotic solvents: Phase diagrams, crystallography and Raman spectroscopy, Phys. Chem. Chem. Phys. 2002, 4 (24), 6063-6071.

(45) Ueno, K.; Tatara, R.; Tsuzuki, S.; Saito, S.; Doi, H.; Yoshida, K.; Mandai, T.; Matsugami, M.; Umebayashi, Y.; Dokko, K.; Watanabe, $\mathrm{M}$., Li(+) solvation in glyme-Li salt solvate ionic liquids. Phys. Chem. Chem. Phys. 2015, 17 (12), 8248-57.

(46) Shannon, R. D., Revised effective ionic radii and systematic studies of interatomic distances in halides and chalcogenides. Acta Crystallographica Section A 1976, 32 (5), 751-767.

(47) Ravel, B.; Newville, M., ATHENA, ARTEMIS, HEPHAESTUS: data analysis for X-ray absorption spectroscopy using IFEFFIT. J. Synchrotron Radiat. 2005, 12 (Pt 4), 537-41.

(48) Frisch, M. J.; Trucks, G. W.; Schlegel, H. B.; Scuseria, G. E.; Robb, M. A.; Cheeseman, J. R.; Scalmani, G.; Barone, V.; Petersson, G. A.; Nakatsuji, H.; Li, X.; Caricato, M.; Marenich, A. V.; Bloino, J.; Janesko, B. G.; Gomperts, R.; Mennucci, B.; Hratchian, H. P.; Ortiz, J.
V.; Izmaylov, A. F.; Sonnenberg, J. L.; Williams; Ding, F.; Lipparini, F.; Egidi, F.; Goings, J.; Peng, B.; Petrone, A.; Henderson, T.; Ranasinghe, D.; Zakrzewski, V. G.; Gao, J.; Rega, N.; Zheng, G.; Liang, W.; Hada, M.; Ehara, M.; Toyota, K.; Fukuda, R.; Hasegawa, J.; Ishida, M.; Nakajima, T.; Honda, Y.; Kitao, O.; Nakai, H.; Vreven, T.; Throssell, K.; Montgomery Jr., J. A.; Peralta, J. E.; Ogliaro, F.; Bearpark, M. J.; Heyd, J. J.; Brothers, E. N.; Kudin, K. N.; Staroverov, V. N.; Keith, T. A.; Kobayashi, R.; Normand, J.; Raghavachari, K.; Rendell, A. P.; Burant, J. C.; Iyengar, S. S.; Tomasi, J.; Cossi, M.; Millam, J. M.; Klene, M.; Adamo, C.; Cammi, R.; Ochterski, J. W.; Martin, R. L.; Morokuma, K.; Farkas, O.; Foresman, J. B.; Fox, D. J. Gaussian 16 Rev. C.01, Wallingford, CT, 2016.

(49) Becke, A. D., Density - functional thermochemistry. III. The role of exact exchange. J. Chem. Phys. 1993, 98 (7), 5648-5652. (50) McLean, A. D.; Chandler, G. S., Contracted Gaussian basis sets for molecular calculations. I. Second row atoms, $\mathrm{Z}=11-18$. $J$. Chem. Phys. 1980, 72 (10), 5639-5648.

(51) Krishnan, R.; Binkley, J. S.; Seeger, R.; Pople, J. A., Self consistent molecular orbital methods. XX. A basis set for correlated wave functions. J. Chem. Phys. 1980, 72 (1), 650-654.

(52) Blaudeau, J. P.; McGrath, M. P.; Curtiss, L. A.; Radom, L., Extension of Gaussian-2 (G2) theory to molecules containing thirdrow atoms K and Ca. J. Chem. Phys. 1997, 107 (13), 5016-5021.

(53) Plimpton, S., Fast Parallel Algorithms for Short-Range Molecular-Dynamics. J. Comput. Phys. 1995, 117 (1), 1-19.

(54) Mamatkulov, S.; Schwierz, N., Force fields for monovalent and divalent metal cations in TIP3P water based on thermodynamic and kinetic properties. J. Chem. Phys. 2018, 148 (7), 074504. (55) Bayly, C. I.; Cieplak, P.; Cornell, W. D.; Kollman, P. A., A Well-Behaved Electrostatic Potential Based Method Using Charge Restraints for Deriving Atomic Charges - the Resp Model. J. Phys. Chem. 1993, 97 (40), 10269-10280.

(56) Wang, J.; Wolf, R. M.; Caldwell, J. W.; Kollman, P. A.; Case, D. A., Development and testing of a general amber force field. $J$ Comput. Chem. 2004, 25 (9), 1157-74.

(57) Wang, J.; Wang, W.; Kollman, P. A.; Case, D. A., Automatic atom type and bond type perception in molecular mechanical calculations. J. Mol. Graph. Model. 2006, 25 (2), 247-60.

(58) Hockney, R. W.; Eastwood, J. W., Computer simulation using particles. 1988. 